\title{
Article
}

\section{Modeling and Control of a Modular Iron Bird}

\author{
Luciano Blasi ${ }^{1}\left(\mathbb{D}\right.$, Mauro Borrelli $^{2}$, Egidio D'Amato ${ }^{3, *} \mathbb{C}$, Luigi Emanuel di Grazia ${ }^{1}\left(\mathbb{D}\right.$, Massimiliano Mattei ${ }^{4}(\mathbb{D}$ \\ and Immacolata Notaro ${ }^{1}$ (1)
}

1 Department of Engineering, University of Campania Luigi Vanvitelli, 81031 Aversa, Italy; luciano.blasi@unicampania.it (L.B.); luigiemanuel.digrazia@unicampania.it (L.E.d.G.); immacolata.notaro@unicampania.it (I.N.)

2 Protom Group, 81043 Naples, Italy; mauro.borrelli@protom.it

3 Department of Science and Technology, University of Naples Parthenope, 81043 Naples, Italy

4 Department of Electrical Engineering and Information Technologies, University of Naples Federico II, 80125 Naples, Italy; massimiliano.mattei@unina.it

* Correspondence: egidio.damato@uniparthenope.it

Citation: Blasi, L.; Borrelli, M.; D'Amato, E., di Grazia, L.E.; Mattei, M.; Notaro, I. Modeling and Control of a Modular Iron Bird. Aerospace 2021, 8, 39. https://doi.org/10.3390/ aerospace 8020039

\section{Academic Editor: Andreas}

Strohmayer

Received: 15 December 2020

Accepted: 29 January 2021

Published: 2 February 2021

Publisher's Note: MDPI stays neutral with regard to jurisdictional clai$\mathrm{ms}$ in published maps and institutional affiliations.

\section{Copyright: @ 2021 by the authors. Li-} censee MDPI, Basel, Switzerland. This article is an open access article distributed under the terms and conditions of the Creative Commons Attribution (CC BY) license (https:// creativecommons.org/licenses/by/ $4.0 /)$.

\begin{abstract}
This paper describes the control architecture and the control laws of a new concept of Modular Iron Bird aimed at reproducing flight loads to test mobile aerodynamic control surface actuators for small and medium size aircraft and Unmanned Aerial Vehicles. The iron bird control system must guarantee the actuation of counteracting forces. On one side, a hydraulic actuator simulates the hinge moments acting on the mobile surface due to aerodynamic and inertial effects during flight; on the other side, the actuator to be tested applies an active hinge moment to control the angular position of the same surface. Reference aerodynamic and inertial loads are generated by a flight simulation module to reproduce more realistic conditions arising during operations. The design of the control action is based on a dynamic model of the hydraulic plant used to generate loads. This system is controlled using a Proportional Integral Derivative control algorithm tuned with an optimization algorithm taking into account the closed loop dynamics of the actuator under testing, uncertainties and disturbances in the controlled plant. Numerical simulations are presented to show the effectiveness of the proposed architecture and control laws.
\end{abstract}

Keywords: iron bird; hydraulic system; flight simulator; force control; PID control

\section{Introduction}

An iron bird is often defined as an "aircraft which does not fly", used to validate the design and verify performance and stability [1] of aircraft components and systems. It is a mechanical representation of aircraft systems, including actuators, arranged on a frame instead of being inside the fuselage or the wings, completely visible, to test the integration of components as the integration of the actuation systems for aerodynamic surfaces and landing gears into the airframe, and their links to the power supplies and the flight control system.

Since the beginning of aviation, giants steps have been made on actuator technology. Currently, fly-by-wire aircraft use hydraulically supplied actuators in order to control mobile surfaces, but the birth of the All (or More) Electric Aircraft philosophy is changing this paradigm towards increasing the use of electrically supplied actuation systems that is usually called power-by-wire (PBW) actuation.

The advantages in using electrical versus hydraulic power on aircraft are well described in [2-5]. Good power density at the level of power network, more efficiency, more options and ease of command, dynamic reconfiguration of power paths are some of them. However, the technology maturity level of PBW is still low in terms of returns of operational experience. Moreover, some technological issues as poor local exchange of heat generated by energy losses have to be studied to increase their diffusion. 
Electro-Mechanical Actuators (EMAs) represent a very good alternative also for small commercial aicraft and UAVs, because of the lower cost and the general lower maintenance effort needed with respect to Electro-Hydraulic Actuators (EHAs).

One of the earliest studies on EMA is [6], where the researches completed by Boeing and Rockwell in the eighties are summarized. Boeing concluded that their baseline aircraft would remain roughly the same mass when switched to EMAs, Rockwell predicted an increase in mass, but in both cases, when EMAs were introduced, the mass of the aircraft secondary power systems decreased.

In [7], a review of EMAs is presented, starting from a brief history on the use of this type of actuators on aircraft. It also explains the main ways to test an EMA, from tests in a room temperature situation, to tests in a thermal vacuum environment, to tests on an iron bird. Generally speaking, the iron bird testing is intended to validate also the linkages of the EMAs with other systems, e.g., the power system and the Flight Control System (FCS).

Iron birds are useful in both industrial and scientific worlds. In the literature, although several authors use iron birds to prove the effectiveness of their solution about flight control algorithms, without focusing on its design, their works represent useful examples and the state of the art about this topic. In [8], Airbus explains how the electrical flight control system used on its aircraft is validated through iron bird testing. In [9], the power plant system of a tilt rotor UAV was verified by means of iron bird ground tests. In [10], a modular iron bird was designed to test new concepts in the flight control area, however, the modules are used for a specific aircraft. In [11], a new methodology for Prognostic Health Management systems of electro-mechanical flight control validation using an iron bird is proposed. The MIB (Modular Iron Bird), which is currently in the construction phase at PROTOM, developed in collaboration with the University of Campania "L.Vanvitelli", is a new concept of geometrically simplified and modular iron bird to perform verification tests of equipment developed for FCSs of small/medium aircraft belonging to the general aviation and unmanned aerial vehicles. It is mainly designed to test the control and actuation system moving the aerodynamic control surfaces and their integration in the flight control system. On the other hand, the test objective is quite extensive, ranging from the analysis of the actuator dynamic response, stability, and accuracy, to the efficiency and power capability, to the response to fault.

Usually, iron birds are custom ground-based test device used for prototyping and integrating aircraft systems (e.g., actuators) during the development of new aircraft designs. Systems are installed into the iron bird so their functions can be tested both individually and in correlation with other systems. They are expensive and often not reusable, being economically inaccessible for many small companies. However, the growth of unmanned aircraft market and the lowering of costs in the design of small aircraft and their actuators, makes attractive the use of a network of affordable facilities able to test systems with limited costs. The MIB architecture tries to give an answer to this increasing need.

The paper is organized as follows. Section 2 deals with the MIB control system architecture description. The mathematical model of the plant to design and validate the proposed control laws is described in Section 3, whereas in Section 4 the force control law is presented together with the algorithm used to tune the control gains. Finally Section 5 illustrates some numerical simulation results.

\section{The MIB Testing Facility}

The basic elements composing MIB are:

- the Data Acquisition and Control System (DACS). This is deployed on different hardware components, namely:

- the Real-Time Process Controller (RTPC) implementing the so called Process Control Algorithms for the tracking of desired loads on the aerodynamic surfaces and the actuator unit under test reference positions; 
- the host PC implementing the User Interfaces (UI) for test preparation, on-line monitoring of the test variables, data archiving, post-processing functions and off-line visualization of the test results;

- a given number of Test Stands (TS) (see Figure 1), actually five, which are composed of:

- a loading hydraulic actuator linked to a rigid mobile surface;

- a set of pressure, position and load sensors, needed for control purposes and to acquire and archive test data;

- the EMA Unit Under Testing (UUT) which is mechanically loaded by the hydraulic actuator;

- the Hydraulic Power Unit (HPU) to supply hydraulic pressure to the actuators on all the TSs;

- $\quad$ the Electrical Power Systems (EPSs).

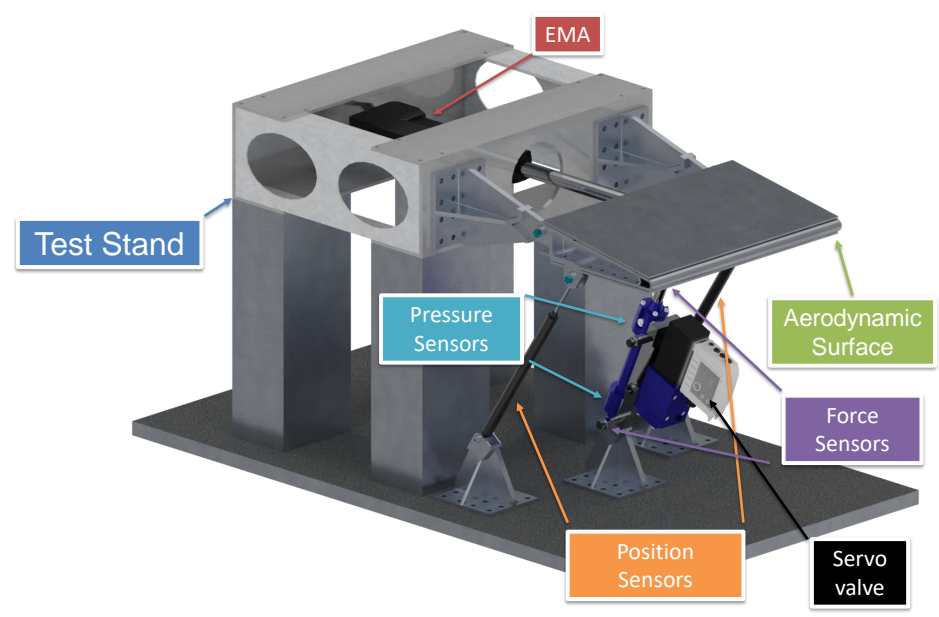

Figure 1. MIB (Modular Iron Bird) Test Stand overview.

The modularity of the proposed Iron Bird is based on the presence of several TS that can adapt to different actuators and layouts; actuators can be tested in parallel or one at a time. Also the hydraulic actuator simulating the aerodynamic and inertial loads can be chosen in function of the loads requested by the test. At the moment, a single rod actuator is adopted to mount a double load sensor, but in future a different actuator can be mounted. Moreover the flexibility offered by the automation system allows to plan different tests including those simulating the aircraft flight and related maneuvers.

\subsection{The Process and Automation Control System}

As shown in Figure 2, the MIB Process Control System implements the following subsystems:

- the test set up and automation functions (Green blocks),

- the real time simulator of the flight dynamics including flight controllers (Blue blocks),

- the actuators and sensor for the force control (Red blocks),

- the EMA actuator UUT (Dark Red block),

- the estimation of the surface position, the estimation of the force acting on the aerodynamic surface, and both the position and force controllers (Yellow blocks). 


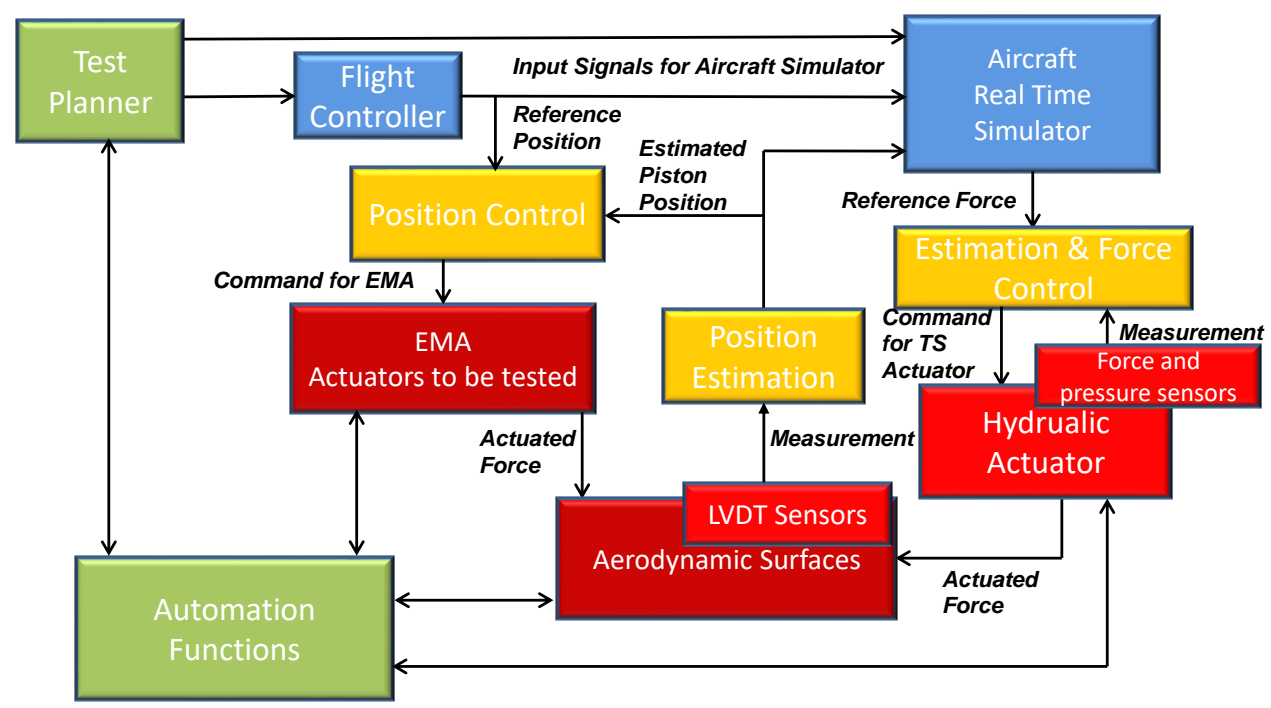

Figure 2. MIB Automation and Control System Architecture.

Red, dark red and yellow blocks are replicated for each TS active.

The MIB Test Planner (TP) manages the test setup procedure implementing the UI, and it is able to generate the input signals for the real time simulator and the reference signals to be passed to the RTPC.

The Automation Function block implements the functions to monitor the overall system health. These functions are implemented with a time step of $0.1 \mathrm{~s}$.

The MIB Aircraft Real Time Simulator (ARTS) is a flight simulator, implementing the equations of the rigid body aircraft dynamics with moving surfaces, including the equations to compute hinge moments on mobile surfaces because these are needed to calculate the flight loads on EMA actuators. The use of simulators in the aircraft design and testing phase is well recognized by the scientific community [12].

The ARTS is also connected with a simulator of the flight control laws. Its inputs are the mobile surface positions, measured by sensors if the related stand is active, otherwise the desired position from the flight control laws is used. In this case the reference commands to the flight controller are produced by the TP with a time step of $0.1 \mathrm{~s}$. The ARTS outputs are the loads to be actuated on the mobile surface, and hence to be passed to the Force Control block as reference signals. Gravity effects due to the aerodynamic surface installation are taken into account and compensated before generating reference loads.

Although this can be easily replaced, the standard flight control law module has a classical structure for fixed wing aircraft, and is based on three nested loops (see Figure 3, namely: a Stability Augmentation System (SAS), a Control Augmentation System (CAS), and an outer Autopilot. These loops can be activated by the User.

SAS control action implements a pitch, roll and yaw damper. CAS implements both a pitch and roll rate control. Finally the autopilot can control altitude, true air speed, and heading.

Due to the use of Matlab/Simulink simulation blocks, both the rigid six degrees of freedom (DoF) aircraft model with moving surfaces and the flight control law implemented can be readily replaced with a more detailed model including flexibility or other phenomena (e.g., ground effects during landing and take-off), and more complex control laws. 


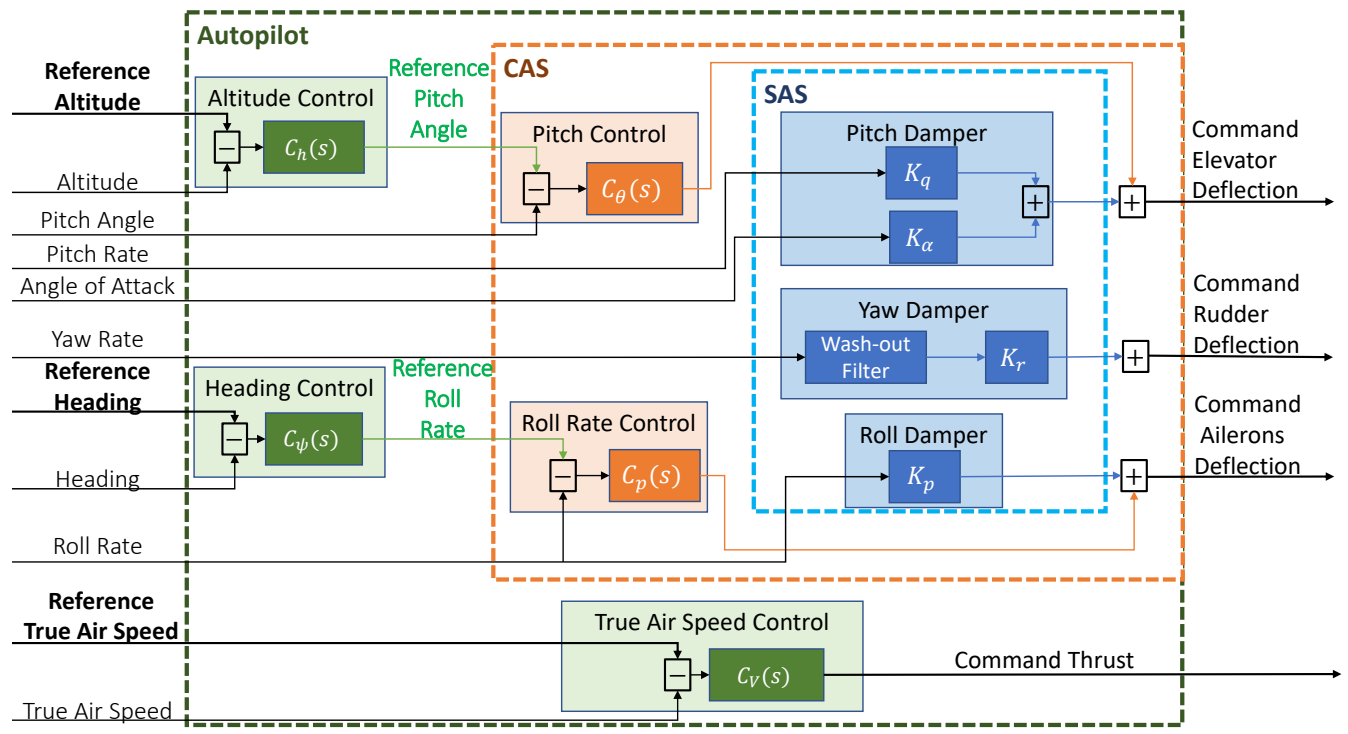

Figure 3. Schematic of the Flight Control Laws.

The Force Estimation and Control block implements the algorithm to estimate and control the load on the mobile surface and hence on UUT. The input to this block are the reference force to be actuated, the measurements from load cells and pressure sensors, and the position of the aerodynamic surface. The output is the command to the servo-valve controlling the flow-rates to the hydraulic actuator. Two force measurements are available at the top and the bottom of the hydraulic cylinder. On the basis of these measurements, pressure measurements into the cylinder chambers, and a position measurements to correct for geometrical effects, a more reliable estimation is obtained via Kalman Filtering.

Similarly, the Surface Position Estimator block can estimate the position of the mobile surfaces on the basis of the position measurement coming from two LVDTs and a speed measurement produced by a digital encoder. LVDTs are the position sensors shown in Figure 1 from which is possible to calculate the angular position of the mobile surfaces. This estimation block is divided from the Position Control block for flexibility purposes. In fact it may happen that the UUT is already equipped with a position control. In this case the MIB Position Control is disabled but a position estimation is still needed to drive the aircraft simulation.

\subsection{The Test Planner}

The Test Planner is a software module for the test preparation. It implements a GUI (Graphical User Interface) to set test parameters and runs on the host PC, in order to supply test parameters to the RTPC. During the test, variables are monitored with a refresh rate of $0.1 \mathrm{~s}$.

Different kind of tests can be performed on MIB depending on the control modes foreseen for the EMA and for the hydraulic system, and on the use of the ARTS. EMA can be controlled in two different ways:

- $\quad$ EMA Direct Control: the EMA is directly controlled, bypassing the Position Control;

- $\quad$ EMA Closed Loop Position Control: the position controller is activated to compute the EMA control signal.

Hydraulic actuators can be controlled in two different ways:

- Hydraulic system Direct Control: the Force Controller is disabled in order to directly control the valve input signal. This test type can be useful in the first phases of the plant operation, in order to identify parameters of the hydraulic system dynamic model;

- Hydraulic system Closed Loop Control: the Force Controller is enabled and computes the servo-valve command on the basis of reference forces.

Finally, the ARTS can be operated in two different ways: 
- Pre-programmed mode: the ARTS simply forwards waveforms designed through the TP GUI (both reference forces to the hydraulic system, and reference positions to the EMA controller).

- Self-consistent mode: the ARTS, on the basis of a reference manoeuvre defined by the TP, and the measured aerodynamic surface positions, calculates in real time the reference signals to the EMA position controllers and to the force controller.

The TP also provides initial conditions for the flight simulation if the ARTS is enabled. This is obtained via a suite of tools implemented in the TP module, including trim and linearization.

\section{Control Oriented Plant Mathematical Modeling}

Hydraulic systems are typically adopted in iron birds to generate loads for their compactness and performance. However, they also present some modeling and controllability issues, due to uncertainties and hard nonlinear dynamic behaviours. Non-linearities are mainly due to flow rates through servo-valves. Uncertainties and disturbances can derive from pressure fluctuation across the pumps or from fluid physical characteristics, such as the bulk modulus, but also from the deformation of the chambers and piston walls, and other effects related volume uncertainties.

Several modeling approaches can be found in the literature. In [1], modeling is based on Newton equation for UUT piston and for load actuator movement. In [13,14], the model is obtained directly in the Laplace domain for the load actuator. In $[15,16]$, the mathematical model is based on Newton equation for the electro-hydraulic piston movements, and a mass balance is used for servo-valve modeling, controlled with input flow rate. In [17,18], the Newton equation is used for piston displacement: Coulomb friction model is adopted taking into account some model uncertainties. Friction, that is a relevant aspect in this field, is also modeled in [19-21]. Relevant works can be found in [22-26].

The objective of the following preliminary modeling is not to precisely describe the physical phenomenon behind the hydraulic system, but to formulate a sufficiently rich, though simple, parametric model, to be tuned with experimental data collected on the plant, on which a first validation of the controller structure and tuning of the controller gains can be done.

An important source of uncertainty in the modeling of the overall system is the actuator UUT which will change from test to test although, for the validation of the plant control system, a specific and known actuator will be used.

With the above premises, the following main modeling simplifications are made:

- $\quad$ the HPU (a Rexroth Cytropack system) comprehensive of an accumulator and regulation system of the pressure inside the accumulator is modeled as a whole with a simple uncertain dynamics;

- $\quad$ pipes dynamics are neglected. In fact, although they have been modeled, it has been verified in simulation that the dynamics are fast enough with respect to the characteristic times of interest, whereas their friction can be concentrated in the neighbouring elements;

- wall deformation are neglected as their uncertain effect on closed loop control can be somehow evaluated with a larger uncertainties on the air trapped in the hydraulic fluid; - $\quad$ hard non-linearities as backlashes and dead zones and saturation are not taken into account in the controller design phase but simulated in the control performance evaluation.

One single TS is assumed to describe the mathematical modeling in more details. The hydraulic load generation system, schematically shown in Figure 4, is composed of four main elements: an open reservoir, an HPU, an electro-hydraulic servo-valve, and a cylinder connected to the movable surface on which the load is applied. The first two components are common to all the TSs. 




Figure 4. Schematic of the Hydraulic Load Generation System.

The HPU pump converts mechanical into hydraulic power, injecting fluid in the supply line. An accumulator is included in the power unit. This is a pressure storage reservoir in which a relatively small quantity of fluid is held under a pressure which is regulated by the system to a given value. The accumulator allows to react quickly to a transient flow rate demand, to smooth out possible pulsations, and avoid significant pressure losses. On the other hand the pump guarantees the mass flow rate needed by the hydraulic cylinder to actuate significant forces in short time.

The servo-valve modulates the flow rate into the two cylinder chambers moving the piston that generates the force on the UUT.

Other standard hydraulic and electric components, needed for a correct and safe operation of the plant, are not modeled and described, as not strictly related to process control validation and design. First of all, compressibility of the oil in the hydraulic circuit has to be taken into account because of the high pressure. In fact the fluid density $\rho_{r}$ depends, assuming the definition of isothermal bulk modulus, on the fluid pressure $P_{r}$ :

$$
\rho_{r}=\rho_{0} \cdot \exp \left(\left(P_{r}-P_{0}\right) / \beta\right)
$$

where $\rho_{0}$ is the density at the atmospheric pressure $P_{0}$, and $\beta$ is the fluid bulk modulus.

Due to the presence of the trapped air in the plant, the bulk modulus cannot be assumed constant, and consequently it is modeled as a nonlinear function of the hydraulic pressure:

$$
\beta=\beta_{0} \frac{1+\alpha\left(\frac{P_{0}}{P}\right)^{1 / \gamma}}{1+\alpha \frac{P_{0}^{1 / \gamma}}{\gamma P^{\frac{\gamma+1}{\gamma}}} \beta_{0}}
$$

where $\beta_{0}$ is the fluid bulk modulus at $P_{0}, \alpha$ is the trapped air volume ratio at $P_{0}, P$ is the fluid pressure, $\gamma$ is the air specific heat ratio.

Hydraulic systems need a finite volume of recirculating liquid to work. A reservoir permits to accumulate the fluid getting rid of the trapped air. The reservoir has a breather to maintain the pressure constant at the atmospheric value. The dynamic equations relating volume, pressure and flow rates are the following:

$$
\begin{gathered}
\dot{V}_{r}=q_{r, \text { in }}-q_{r, \text { out }} \\
P_{r}=\rho_{r} g h
\end{gathered}
$$

where $V_{r}$ is the liquid volume in the reservoir, $q_{r, \text { in }}$ and $q_{r, o u t}$ are the input and output volumetric flow rates, respectively, $P_{r}$ is the pressure at the bottom of the reservoir, $g$ is the gravity acceleration, $h=V_{r} / A_{r}$ is the height of fluid column, with $V_{r}$ and $A_{r}$ volume and cross section area of the cylindrical reservoir, respectively. 
The hydraulic pump is a device used to convert mechanical power into hydraulic power. Modern HPUs can adapt fluid flow rate to keep a fairly constant pressure in an accumulator downstream the pump.

This accumulator is used to store a limited amount of fluid to smooth out pressure oscillations and to make the downstream components dynamic response less sensitive to the upstream conditions.

The whole HPU is modeled with the following uncertain first order system:

$$
\begin{gathered}
\dot{P}_{p}=K_{H}\left(q_{p}-q_{v}\right) \\
q_{p}=k_{p}\left(P_{p, r e f}-P_{p}\right)+k_{I} \int\left(P_{p, r e f}-P_{p}\right) d \tau
\end{gathered}
$$

where $P_{p}$ is the pressure in the accumulator. The maximum pressure delivered by the pump is 200 bar. $q_{p}$ and $q_{v}$ are the flow rate provided by the hydraulic pump, and the flow rate across the servo-valve, $K_{H}$ is a constant obtained from the linearization of the system behavior around its operating conditions and is assumed to be uncertain. $P_{p, r e f}$ is the reference pressure in the accumulator controlled by the HPU local pressure control system.

The force control is obtained with a servo-valve converting electrical command signals into a spool valve command to control the flow rate. Under simplifying assumptions and the absence of leakages, the servo-valve dynamics can be approximated as a first order dynamics:

$$
\begin{array}{r}
\dot{X}_{s v}=-\frac{1}{\tau_{s v}} X_{s v}+\frac{u_{s v}}{\tau_{s v}} \\
X_{s v, \text { min }}<=X_{s v}<=X_{s v, \text { max }}
\end{array}
$$

where $X_{s v}$ is the servo-valve spool displacement, $\tau_{s v}$ is the time constant, and $u_{s v}$ is the control action computed on the basis of error between desired force acting on the cylinder and the estimated one, $X_{s v, \min }$ and $X_{s v, \max }$ are the limits on the servo-valve opening variable. The flow rate through the servo-valve is

$$
q_{s v}=C_{d} w X_{s v} \sqrt{\frac{2\left(P_{u}-P_{d}\right)}{\rho_{s v}}}
$$

where $C_{d}$ is the servo-valve discharge coefficient, $w=A_{s v} / X_{s v, \text { max }}$ is the servo-valve area gradient, $A_{s v}$ is the servo-valve port area, $\rho_{s v}$ is the fluid density, $P_{u}$ is the pressure upstream the servo-valve, and $P_{d}$ is the pressure downstream the servo-valve.

Assuming that $P_{i}(i=1,2)$ is the pressure in chamber $i$ with $i=1,2, P_{u}$ and $P_{d}$ are identified on the basis of the servo-valve position. If $X_{s v} \geq 0$, chamber \#1 is connected to the fluid supply line, then $P_{u}=P_{h p}, P_{d}=P_{1}$; if $X_{s v}<0$, chamber \#1 is connected with the return line, then $P_{u}=P_{1}, P_{d}$ is equal to the pressure of the return line that can be assumed as the pressure $P_{r}$ in the reservoir. $\rho_{s v, s}$ and $\rho_{s v, r}$ being the servo-valve densities in the supply and return lines, respectively, the flow rates in the hydraulic actuator chambers are the following:

$$
\begin{array}{r}
q_{s v, 1}= \begin{cases}C_{d} w X_{s v} \sqrt{2\left(P_{h p}-P_{1}\right) / \rho_{s v, s}} & X_{s v} \geq 0 \\
C_{d} w X_{s v} \sqrt{2\left(P_{1}-P_{r}\right) / \rho_{s v, r}} & X_{s v}<0\end{cases} \\
q_{s v, 2}= \begin{cases}C_{d} w X_{s v} \sqrt{2\left(P_{2}-P_{r}\right) / \rho_{s v, r}} & X_{s v} \geq 0 \\
C_{d} w X_{s v} \sqrt{2\left(P_{h p}-P_{2}\right) / \rho_{s v, s}} & X_{s v}<0\end{cases}
\end{array}
$$

Hysteretic effects due to static friction, and deadband, as reported by the servo-valve manufacturer are also included in the dynamic modeling used to validate the control law. 
In the hydraulic actuator, the piston is forced by the pressure difference between two chambers. Volume variation in chamber $i$ is $\dot{V}_{i}=(-1)^{i} \dot{X} A_{i}, i=1,2$. The chamber volume variation is related to pressure variations as follows:

$$
\begin{gathered}
\dot{P}_{i}=\left(q_{i}-\dot{V}_{i}\right) \frac{\beta}{V_{i}} \quad i=1,2 \\
\ddot{X}_{p}=\left(\left(P_{1} A_{1}-P_{2} A_{2}\right)-b_{p} \dot{X}_{p}-k_{p} X_{p}-m_{a c} g \cos \left(X_{p} / l_{a c}\right)+R\right) /\left(m_{p}+J_{a c} / l_{p}^{2}+J_{E M A} / l_{p}^{2}\right)
\end{gathered}
$$

where $X_{p}$ is the piston position with respect to the center of the cylinder, $A_{i}$ the $i$-th chamber cross section, $P_{i}$ the chamber pressure, $q_{i}$ the $\mathrm{i}$-th chamber input volumetric flow rate, $b_{p}$ the damping coefficient, $k_{p}$ the elastic coefficient, $m_{a c}$ is the movable surface mass, $l_{a c}$ the distance between the surface center of mass and the hinge axis, $m_{p}$ the piston mass, $l_{p}$ the distance between the piston and the hinge axis, $J_{a c}$ and $J_{E M A}$ the inertia moments of the surface and the EMA, respectively, with respect to the hinge axis, and $R$ the force generated by EMA. The mechanical linkages are supposed rigid, however backlashes are introduced in the numerical simulations to evaluate their uncertain effects of control laws.

\subsection{EMA Actuator under Testing}

Special attention must be paid to the modeling of the EMA actuator UUT moving the mobile aerodynamic surface. In fact, being the object of the test, its model depends on the particular test itself. For the control system architecture validation and testing a specific EMA is used. This is modeled with a first order dynamic system

$$
\dot{R}=-\frac{1}{\tau_{E M A}} R+\frac{u_{E M A}}{\tau_{E M A}}
$$

where $R$ is the generated force, $\tau_{E M A}$ is the EMA time constant, $u_{E M A}$ is the control action generated by the position controller. In addition a rate limiter and a saturation is added for the force controller performance assessment.

In case the UUT comes as a black box to be tested, a procedure to identify the EMA dynamic model including non-linearities, based on the use of Neural Networks and Nonlinear AutoRegressive eXogenous (NARX) dynamic models [27-30], has been formulated and validated with numerical simulations.

\section{Force Control Algorithm}

An interesting problem to be taken into account for the Process Controller, is that force control has to counteract the reaction of a position controller implemented on the UUT actuator side.

For this reason, the Force Control Algorithm must satisfy very tight requirements on the closed loop speed of response and the capability to counteract disturbances induced by the position control of the UUT.

In fact, both the hydraulic and EMA actuators are mechanically linked to the movable surface and each controller becomes a source of disturbance for the other. Looking at force control, the piston speed induced by position control, causes a variation of the volume of the two cylinder chambers, namely $V_{i}, i=1,2$. Therefore, since the pressure rate in each chamber $\dot{P}_{i}, i=1,2$ depends on the volume derivative $\dot{V}_{i}$ according to (12), if this effect is not properly compensated by dumping the necessary amount of fluid from one chamber to the other, strong overshoots of the controlled force occurs.

In the scientific literature, this problem has been dealt with in [1], where a ProportionalIntegral (PI) controller with feed-forward compensation is adopted to counteract UUT speed disturbances on force control. This control approach, called traditional, suffers from synchronization accuracy issues. In [31] structured guidelines for the synthesis of dynamic force simulators that are required for the testing of high speed aerospace actuators are developed. Realistic and proven solutions at both test bench hardware and control 
design levels are provided. In [13], asynchronous controller is used to to regulate the loading actuator operating velocity synchronously with UUT actuator so as its actuator motion disturbance can be decoupled. In [32], the traditional control is achieved with an adaptive control approach based on the relationship between speed and current in electro-mechanical actuators.

In [15], it is shown that the closed loop poles of the UUT, controlled in position, are zeroes of the force driven open loop transfer function for load actuation. This leads to a performance limitation when a PID control is used for force control. A Quantitative Feedback Theory (QFT) based control technique is proposed to overcome this problem. QFT is used also in [16,33,34], a force controller is designed with a loop shaping technique.

In [35], several techniques are analysed: feedback force control with force direct measurement using a PI action, combinations of state feedback control schemes with state observers and velocity feedforward compensation actions. In [36], a PID controller is used and disturbances due to UUT speed are compensated with a signal proportional to a model based estimation of UUT acceleration.

A PID controller is proposed in [37], where three tuning methodologies are presented: optimal time tuning PID, optimal frequency tuning, and multi-objective PID. Also in [38], a PID is used for both load actuation and for rejecting UUT velocity disturbances. This controller is also used in [39] for servo-valve pressure control.

In [40], a feedforward controller and a feedforward inverse control with disturbance observer are used for load actuation. The former is used to reject disturbances due to UUT movements, the latter is used for the other disturbances. In [17,41] adaptive reference controls are presented. In [42], a fuzzy logic MIMO controller is proposed. Fuzzy logic is also used in $[19,43]$ to tune a PID, in order to increase robustness. Fuzzy logic is also used in [44]. In [45], a Minimal Control Synthesis with integral action is used with adaptive gains, while in [20], a back-stepping based controller is adopted. Other works are based on $H_{\infty}$ control [46], nonlinear adaptive optimal control strategies [47], sliding mode in [48] and an adaptive decoupling synchronous controller in [49].

In [50], a Model Predictive Controller is proposed by the authors dealing with loads generated by fast moving EMAs. The proposed controller uses a simplified model of hydraulic plant, achieved by neglecting the faster dynamics of pump, reservoir, pipes and accumulator. However, the computational burden of the predictive approach does not yet allow an online implementation with low-cost hardware solution.

The present work is focused on a preliminary classical PID control, tuned on the mathematical model of the plant, in view of a model calibration, controller parameters re-tuning, and first closed loop tests.

In fact force control is based on a Proportional-Integral-Derivative (PID) scheme, which computes the input to the servo-valve in order to act on the input/output flow rate in the two chambers of the hydraulic actuator to control pressure. The closed loop actuator control system has to be tuned to have a dynamic response which is significantly faster than the EMA position control time response. In this way the design of force control can be reasonably decoupled from the position controller dynamics.

Therefore, by taking into account the frequency separation between the two controllers, the force control gains have been optimized to guarantee a certain degree of robustness and given performance.

In practice the following quantities are defined:

- a set of uncertainties, defined in terms of variations with respect to nominal value of the following parameters:

- Bulk modulus $\beta_{0}$

- air trapped volume ratio $\alpha$,

- Servo-valve time constant $\tau_{s v}$.

- Discharge coefficient and servo-valve area product $C_{d} A_{s v}$,

- EMA time constant $\tau_{E M A}$. 
A family of $N_{u}$ plant models, implementing the above uncertainties, is defined:

$$
\begin{aligned}
& \dot{x}_{j}=f_{j}\left(x_{j}, u\right) \\
& y_{j}=h_{j}\left(x_{j}, u\right)
\end{aligned}
$$

$\left(j=1, \ldots, N_{u}\right)$, where $x_{j}, y_{j}$, and $u$ are the state vector, the controlled output (force on the aerodynamic surface) and control input (servo-valve command), respectively;

- a set of $N_{S}$ operating scenarios to evaluate the robust performance of the controller over the $N_{u}$ models by means of the following cost function:

$$
J\left(e_{j}^{k}(\cdot), u(\cdot), x_{0 j}, t_{0}, t_{f}, w\right), \quad k=1, \ldots, N_{S}
$$

with $y_{r e f}^{k}-y_{j}^{k}$ the output tracking error, $y_{r e f, k}$ being the force reference signal, $x_{0 j}$ the initial state at time $t_{0}, t_{f}$ a finite time for the cost function evaluation, and $w$ a suitable vector of weights;

- a parametric structure for the force controller:

$$
u(t)=u_{C L}\left(p, e_{\left[t_{0}, t\right]}(\cdot), t\right)
$$

with $e=y_{r e f}-y$. In our case, the vector $p$ represents the gains of a PID control action to be optimized.

Therefore, the following optimization problem was solved:

$$
\min _{p} \max _{j=1, \ldots, N_{u}} J\left(e_{j}^{k}, u_{C L}, x_{0 j}, t_{0}, t_{f}, w\right)
$$

subject to

$$
\begin{array}{r}
\dot{x}_{j}=f_{j}\left(x_{j}, u\left(p, e_{j}^{k}(t), t\right)\right) \quad, x_{j}\left(t_{0}\right)=x_{0 j} \\
y_{j}=h_{j}\left(x_{j}, u\left(p, e_{j}^{k}(t), t\right)\right) \\
\underline{u} \leq u(t) \leq \bar{u} \\
\underline{x} \leq x_{j}(t) \leq \bar{x}
\end{array}
$$

The above optimization Problem, defined by (19) and (20), was solved in the discrete time using a Genetic Algorithm [51,52].

\section{Numerical Result}

Table 1 reports the main plant parameters used for numerical simulations. A single TS control implementing ailerons tests is considered.

The servo-valve is an adirectional control valve, direct operated, with integrated digital axis controller (IAC Multi Ethernet), Rexroth type 4WRPDH. The servo-valve opening variable in plots is a normalized servo-valve opening.

To optimize the controller gains, the following scenarios were considered:

- Scenarios without the Aircraft simulator:

- force multi step (with increasing amplitude 100, 500 and $1000 \mathrm{~N}$ ), constant pump pressure $(15 \mathrm{MPa})$;

- force multi step with constant pump pressure $(80 \%$ of the nominal $15 \mathrm{MPa})$;

- force multi step with constant pump pressure (120\% of the nominal $15 \mathrm{MPa})$;

- force multi step with sinusoidal pump pressure $(15 \mathrm{MPa}+0.15 \sin (\omega * t) \mathrm{MPa})$.

- Scenarios with the Aircraft simulator:

- Aileron doublet (2.5 deg deflection for $9 \mathrm{~s}$ followed by -2.5 deg deflection for $9 \mathrm{~s}$ );

- Aileron step (2.5 deg deflection). 
In addition, the following model uncertainties were taken into account:

- $\quad \pm 10 \%$ of the nominal bulk modulus at atmospheric pressure;

- $\pm 10 \%$ of the nominal air trapped volume ratio;

- $\pm 10 \%$ of the servo-valve time constant;

- $\quad \pm 10 \%$ of the $C_{d} A_{s v}$ parameter;

- $\pm 10 \%$ of EMA time constant.

Table 1. Plant parameters.

\begin{tabular}{cc}
\hline Parameter & Value \\
\hline Bulk nominal modulus at atmospheric pressure, $\beta_{0}[\mathrm{GPa}]$ & 1.5 \\
Pressure controlled by pump in the accumulator, $P_{h p}[\mathrm{MPa}]$ & 15 \\
Density at atmospheric pressure, $\rho_{0}\left[\mathrm{~kg} / \mathrm{m}^{3}\right]$ & 989 \\
Servo-valve discharge coefficient times Servo-valve hole area, & 0.03 \\
$C_{d} A_{s v}\left[\mathrm{~cm}^{2}\right]$ & 0.01 \\
Servo-valve equivalent time constant, $\tau_{s v}[\mathrm{~s}]$ & 8.00 \\
Chamber cross section, $A\left[\mathrm{~cm}^{2}\right]$ & $5 \%$ \\
Dead volume of the chamber & 1.00 \\
Piston mass, $\mathrm{m}[\mathrm{kg}]$ & 0.01 \\
\hline
\end{tabular}

To test the performance of the force controller, a campaign of simulations was performed. In each simulation, the above uncertainties were considered. In addition the following disturbances or additional phenomena were considered: hysterical effects of the servo-valve and mechanical links, servo-valve dead zone, piston end-stroke.

To evaluate the controller performance, responses to small step inputs $(100 \mathrm{~N}$ for force and $0.1 \mathrm{~cm}$ for position) are considered in the presence of perturbed models. In Table 2, mean values of control performance indexes are shown. In particular, the mean quadratic error (MQE), the overshoot and the settling time (ST) are reported for the worst case. For the settling time the worst case is assumed to be the maximum for force control and the minimum for position control.

Table 2. Controllers performance: Mean Quadratic Error (MQE), Overshoot, Settling Time (ST).

\begin{tabular}{ccc}
\hline Performance Parameters & Force & Position \\
\hline Max MQE & $200 \mathrm{~N}^{2}$ & $4.6 \times 10^{-4} \mathrm{~cm}^{2}$ \\
Max Overshoot & $50 \%$ & $30 \%$ \\
Perturbed ST & $0.24 \mathrm{~s}$ & $0.72 \mathrm{~s}$ \\
\hline
\end{tabular}

In the proposed Simulation \#1, pre-programmed reference force and position signals were considered, as shown in Figures 5 and 6, respectively.

In Figure 7 the normalized servo-valve position time history is shown. Figure 8 shows the pressure provided by the pump including the sinusoidal disturbance. Lastly, in Figures 9 and 10 both cylinder chambers pressure are shown. It is worth noticing that the controlled force results is able to reject the disturbance represented by the piston movement. This is an important characteristic to be sure to evaluate the EMA in a wellemulated scenario.

Simulation \#2, carried out with the same reference signals as Simulation \#1, demonstrates the robustness of the controllers to measurement white gaussian noise on position and force measurements. The same quantities shown for Simulation \#1 are shown in Figures 11-16. The controlled force is able to reject the disturbance represented by the piston movement also in presence of model uncertainties and measurement noise. 


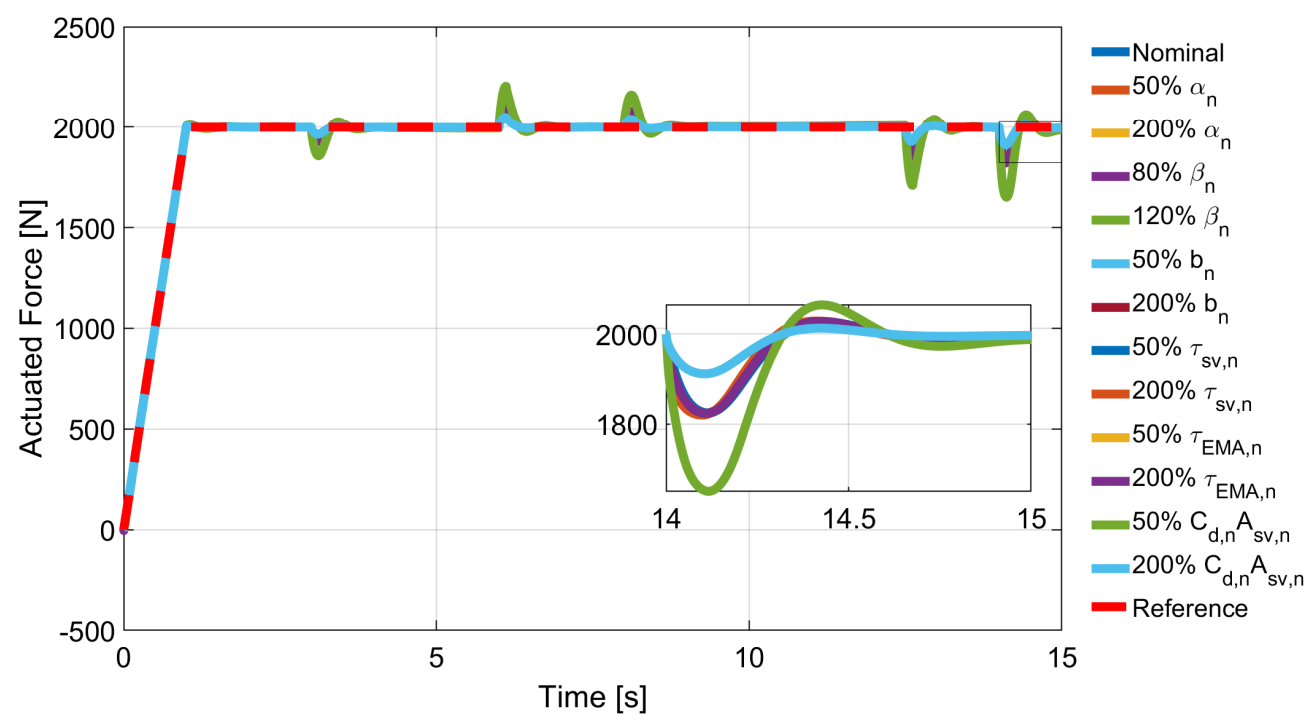

Figure 5. Simulation \#1: Actuated force compared to the reference force.

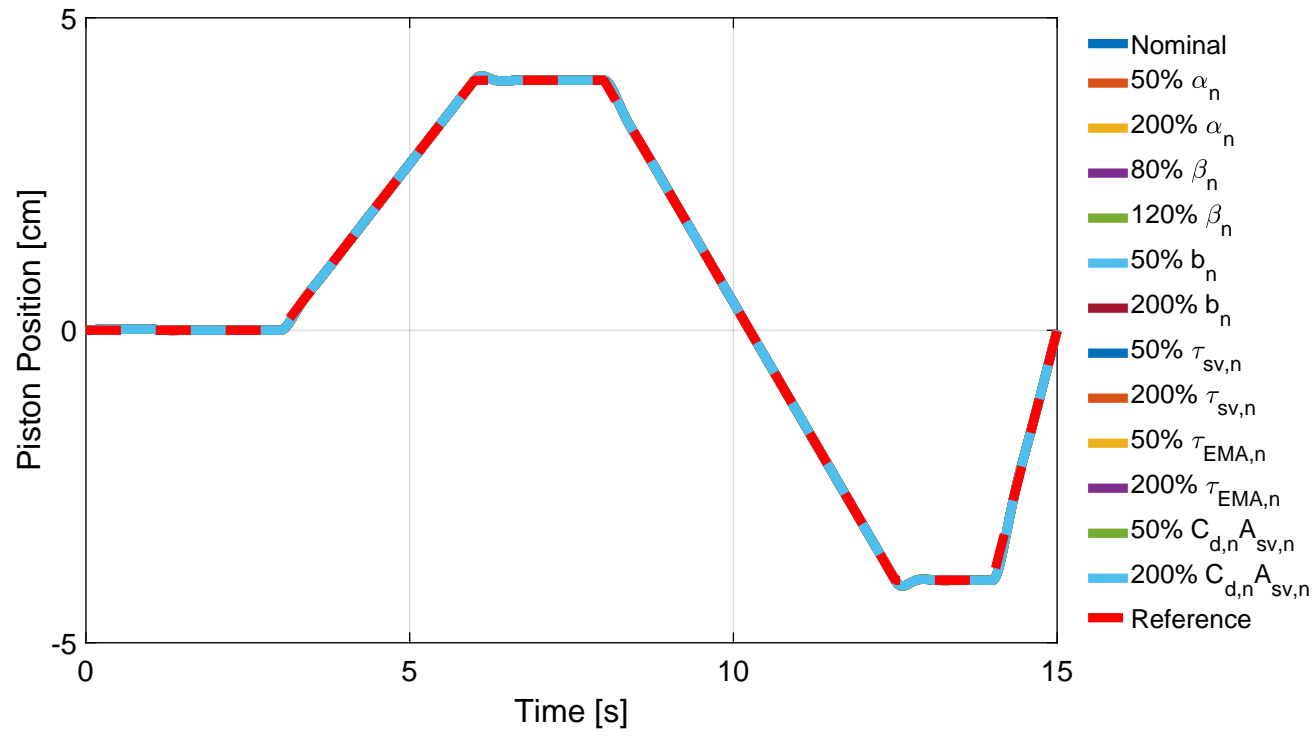

Figure 6. Simulation \#1: Piston Position compared to the reference position.

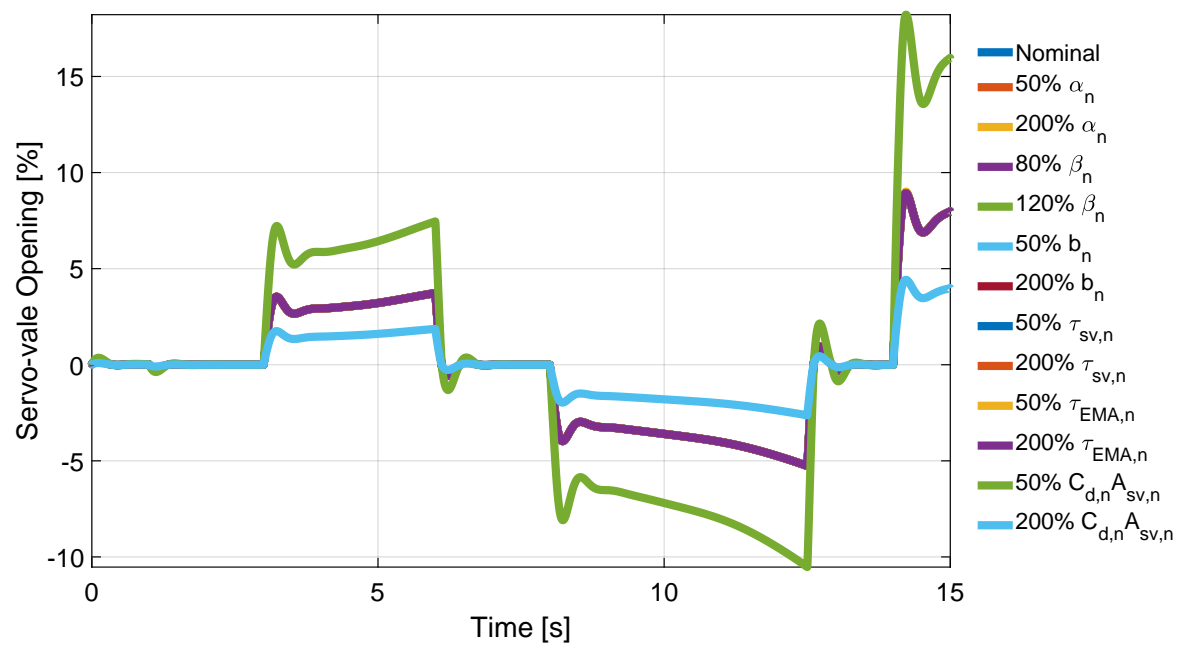

Figure 7. Simulation \#1: Servo-valve opening command. 


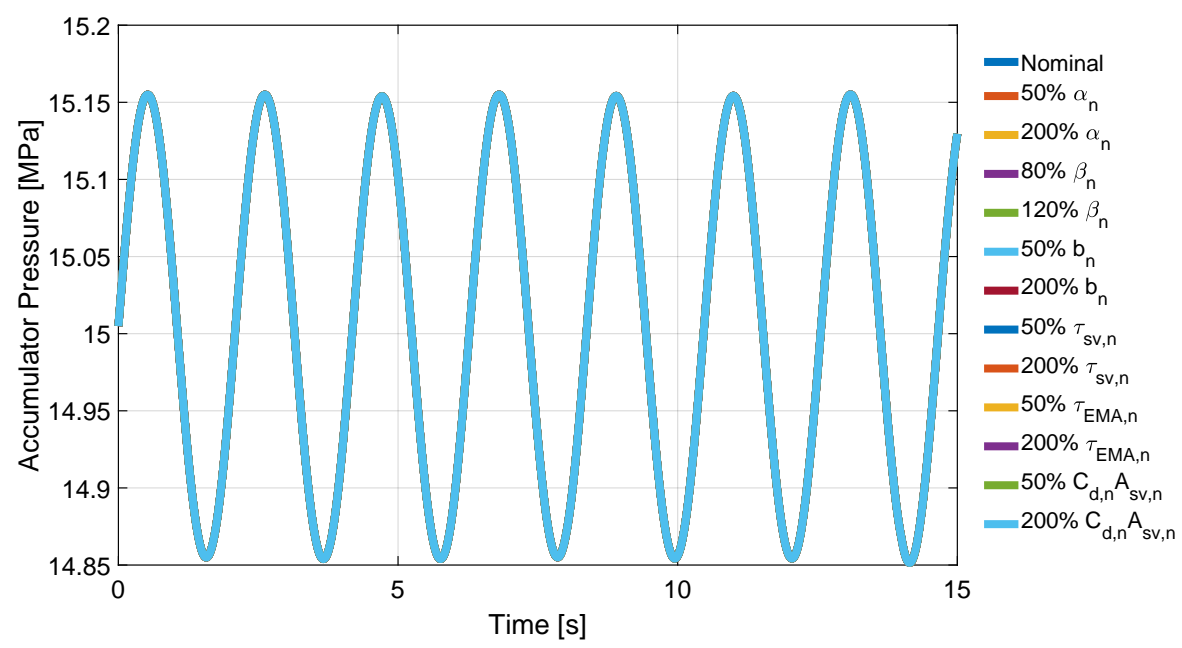

Figure 8. Simulation \#1: Accumulator Pressure.

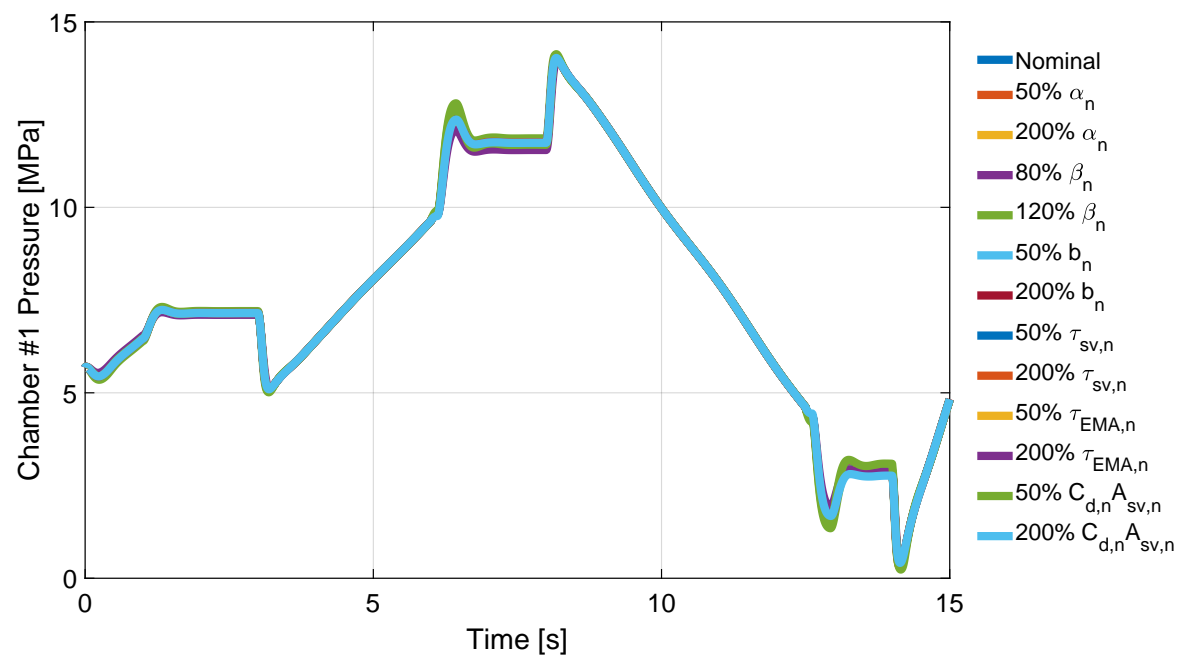

Figure 9. Simulation \#1: Chamber \#1 Pressure.

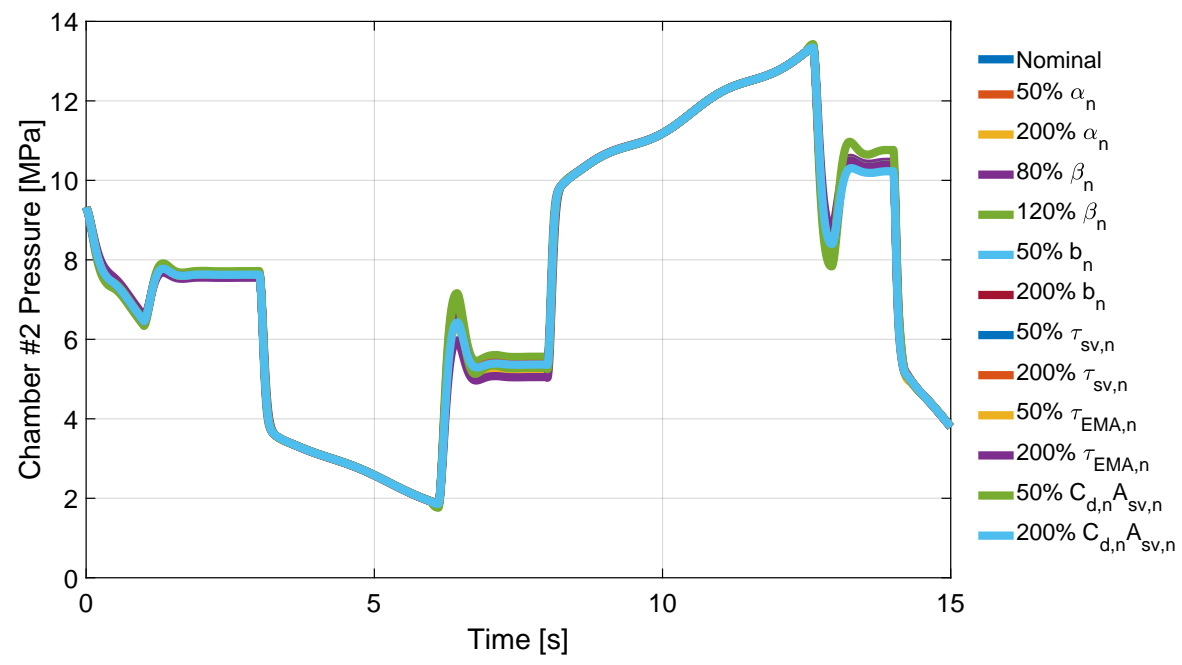

Figure 10. Simulation \#1: Chamber \#2 Pressure. 


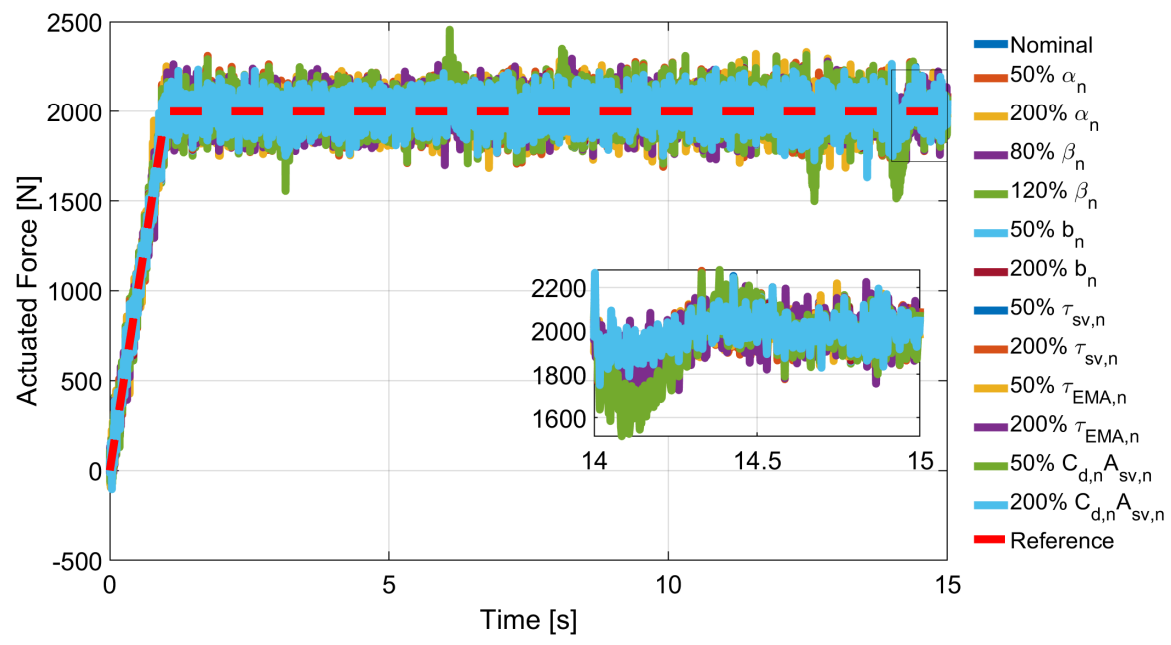

Figure 11. Simulation \#2: Force actuated by the Hydraulic cylinder compared to the reference signal.

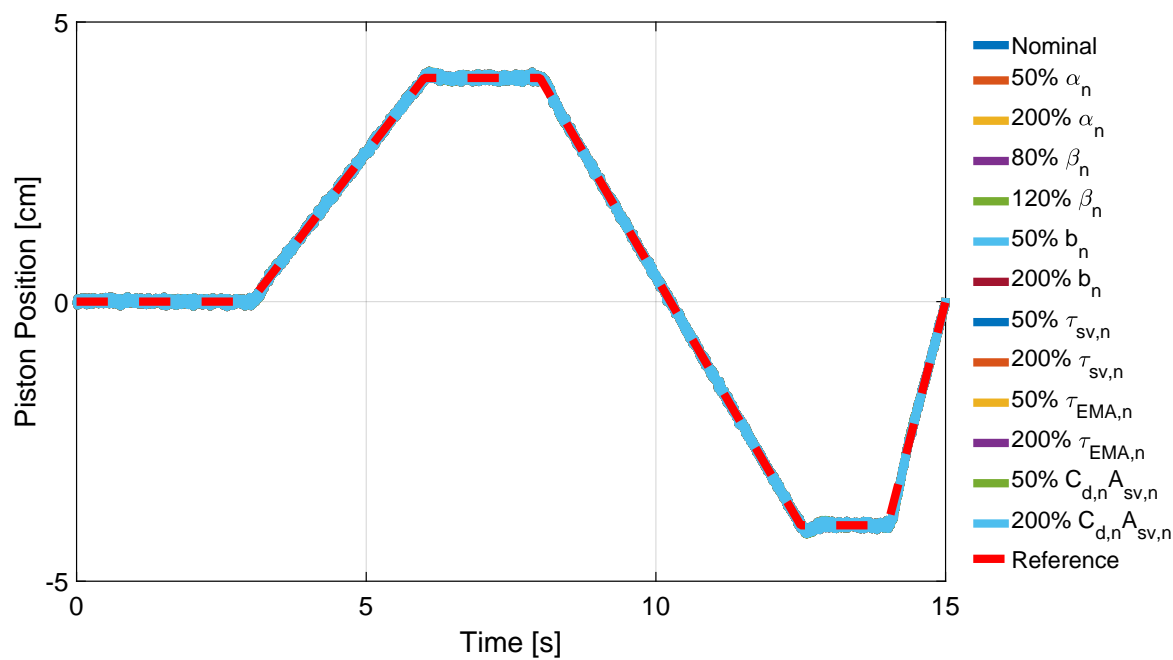

Figure 12. Simulation \#2: Piston Position compared to the reference signal.

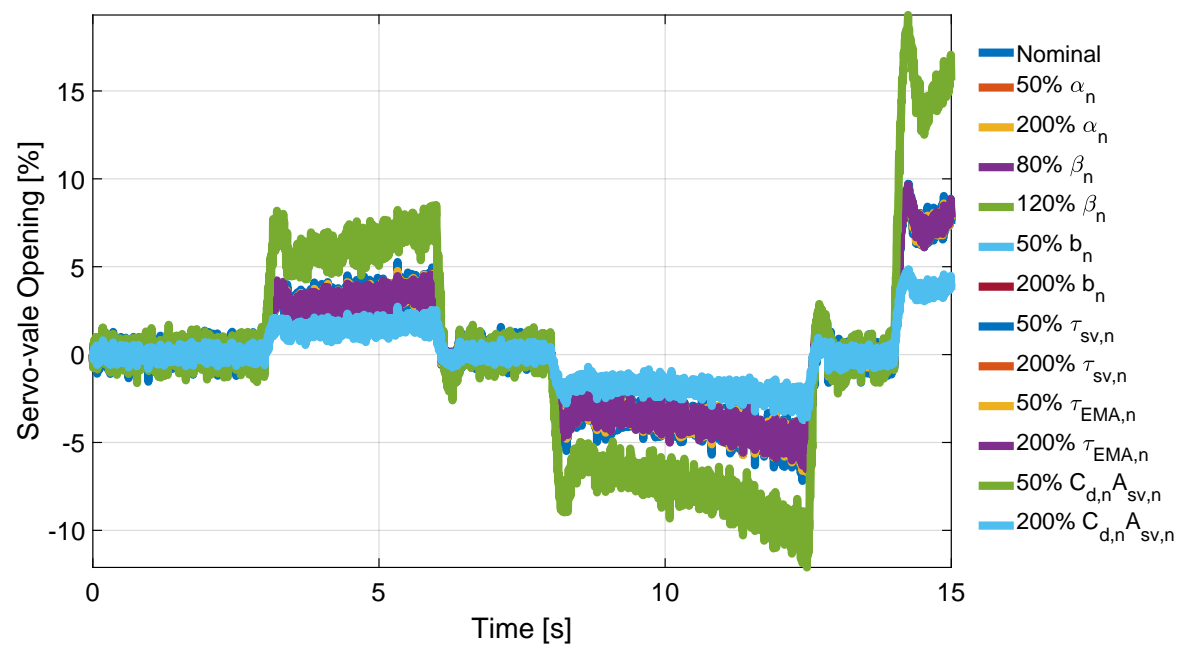

Figure 13. Simulation \#2: Servo-valve opening command. 


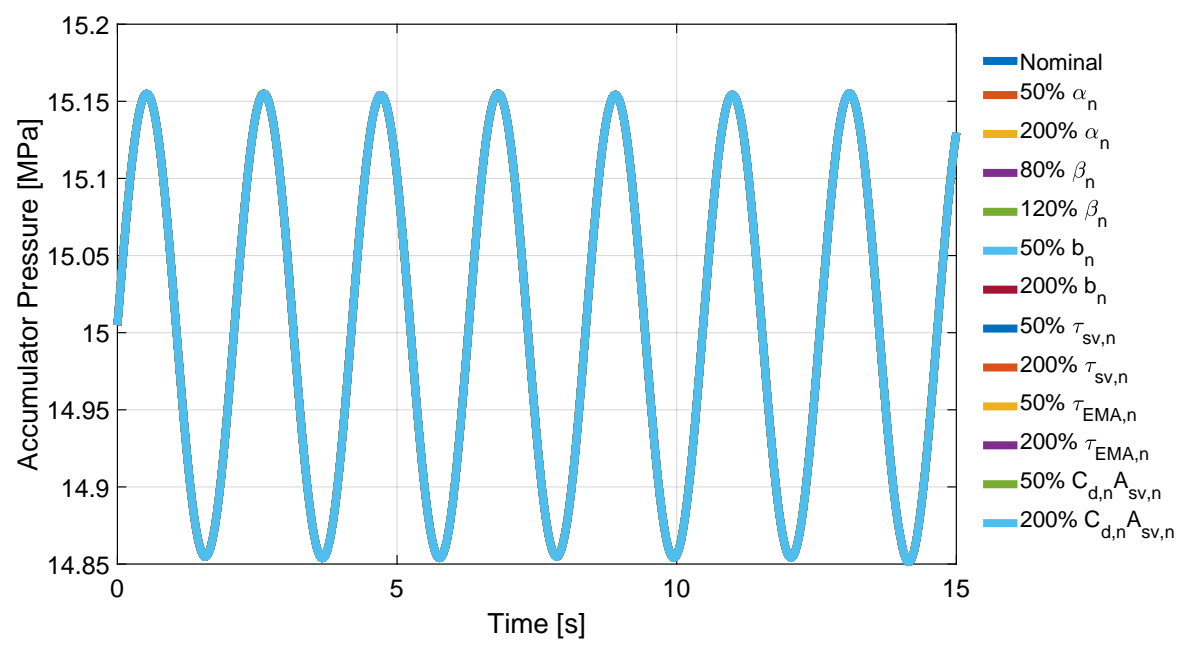

Figure 14. Simulation \#2: Accumulator Pressure.

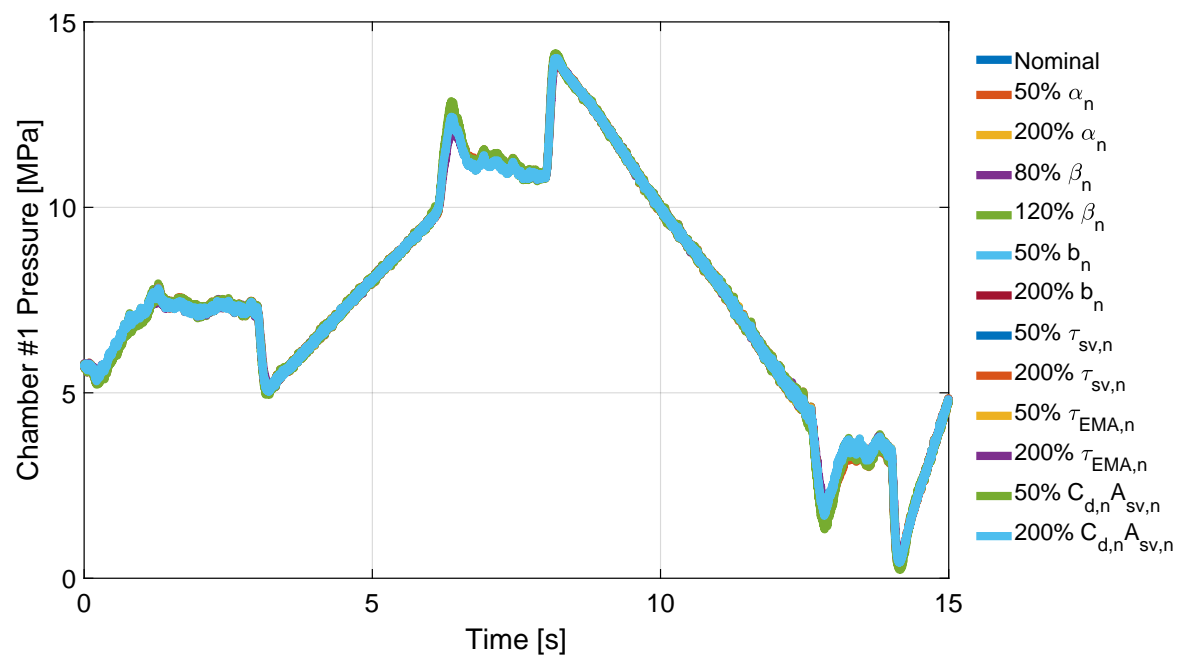

Figure 15. Simulation \#2: Chamber \#1 Pressure.

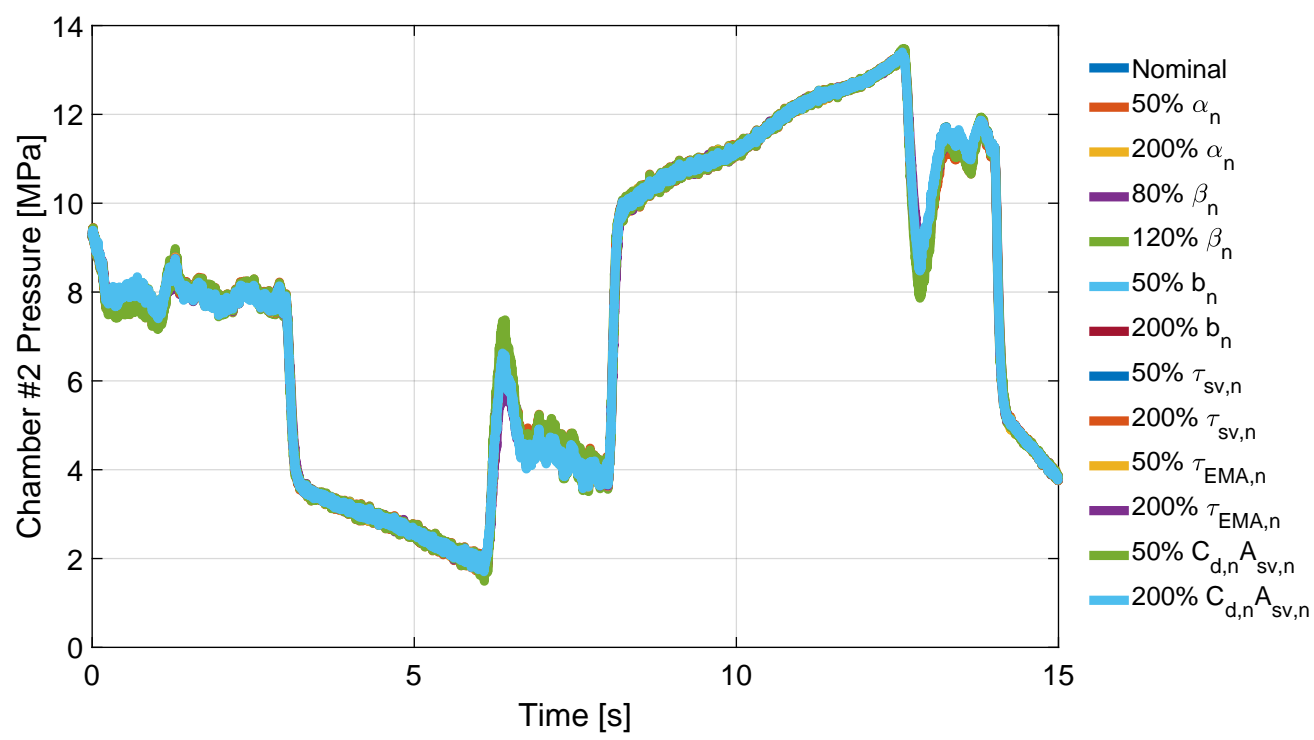

Figure 16. Simulation \#2: Chamber \#2 Pressure. 


\subsection{Numerical Results with the Flight Simulator in the Loop}

An innovative feature of MIB is the capability of reproducing loads provided by a real time flight simulator including control laws.

Several tests involving the ARTS were carried out. In particular the following conditions, implying an aileron deflections, were simulated:

- without FCS:

- a 0.044 rad step on ailerons deflection;

- a \pm 0.044 rad doublet on ailerons deflection;

- $\quad$ with SAS active:

- a 0.044 rad step on ailerons deflection;

- a \pm 0.044 rad doublet on ailerons deflection;

- with CAS active:

- an impulse (1.05 rad/s) on roll rate command;

- a doublet $( \pm 1.05 \mathrm{rad} / \mathrm{s})$ on roll rate command;

- with Autopilot active:

- a step (0.088 rad) on the heading angle reference;

- a ramp $(0.26 \mathrm{rad} / \mathrm{s})$ on heading angle reference;

The Cessna 172 was assumed as reference aircraft, whose main parameters are reported in Figure 17.

In the following Simulation \#3, ARTS was used in "self-consistent mode" without flight control laws, and driven by a doublet input signal to the ailerons shown in Figure 18. The resulting force is shown in Figure 19. The reference force and position signals compared to the actual one in the presence of uncertainties are shown in Figures 20 and 21.

Figures 22 and 23 give an idea of the simulated maneuver, which is a sort of turn. Roll angle and roll angular speed are shown. It can be noted that reference signals produced by the ARTS are like smoothed by the aircraft dynamics. Therefore, force controller provides better results with respect to sharp reference signals.

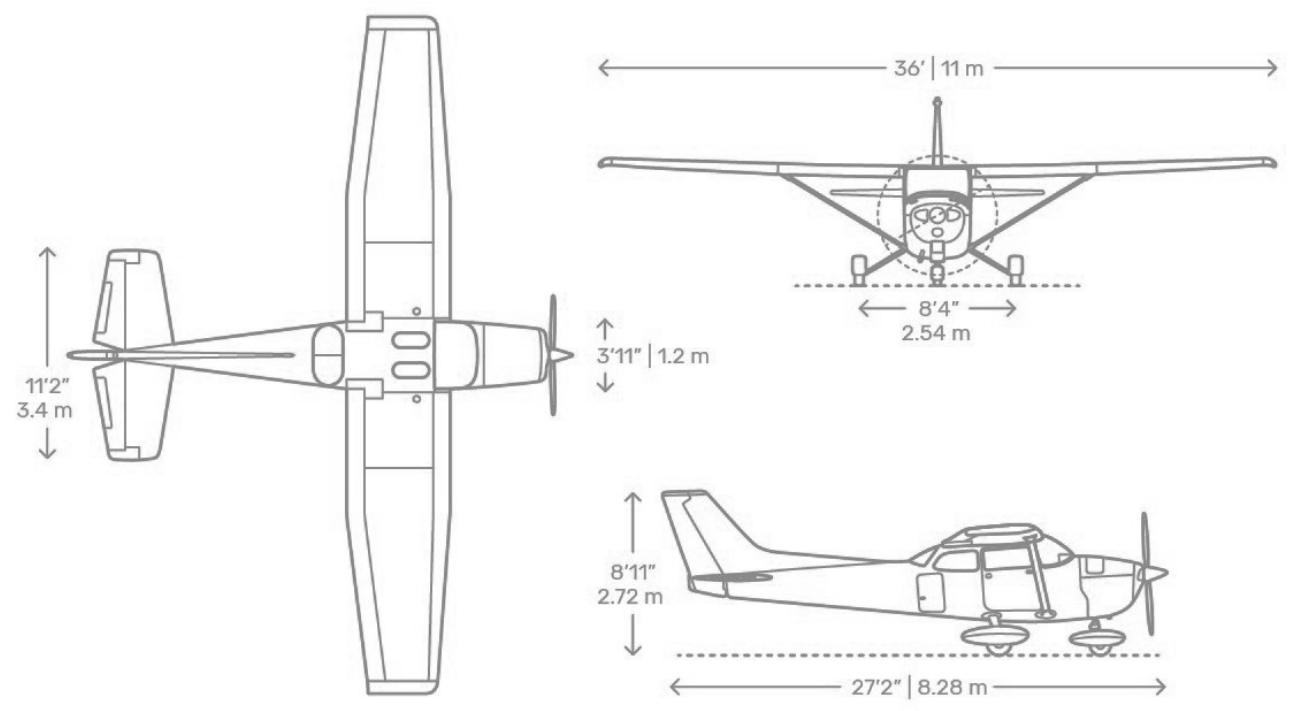

Figure 17. Simulated Aircraft-Cessna 172. 


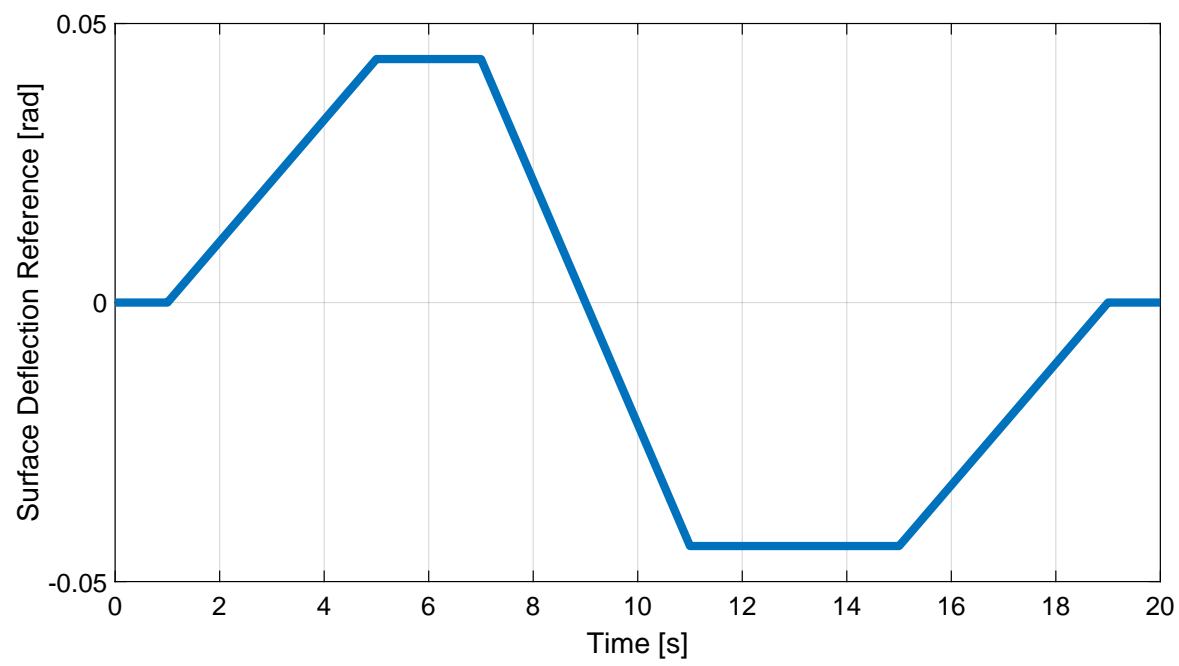

Figure 18. Simulation \#3: Surface Deflection Reference.

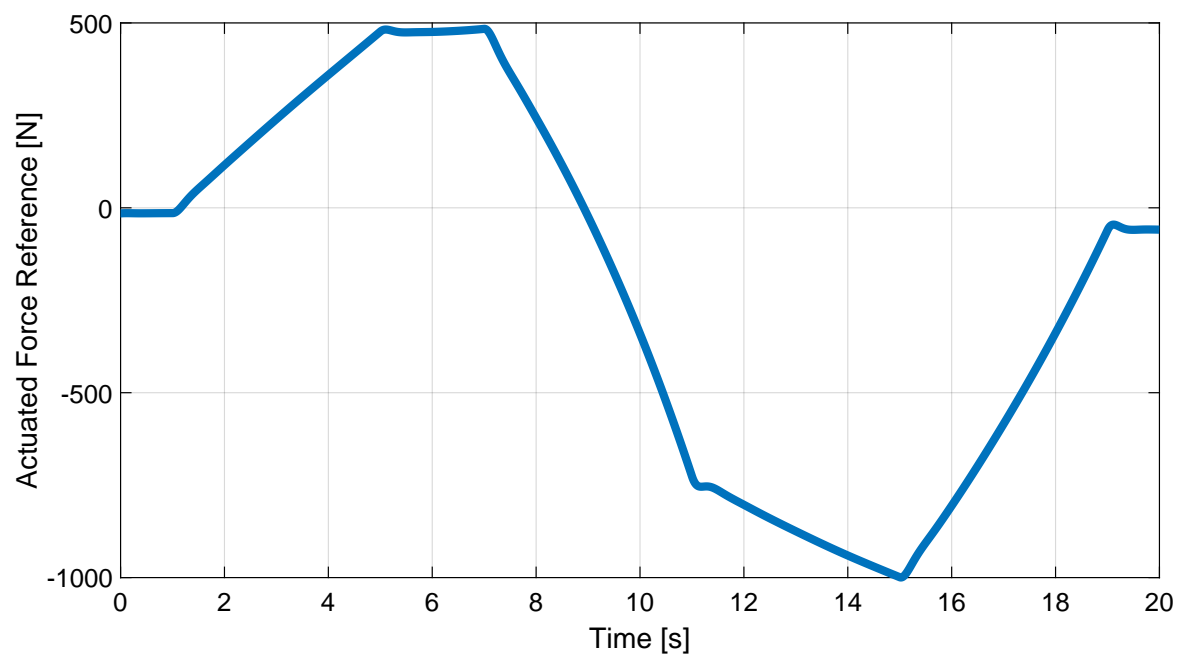

Figure 19. Simulation \#3: Actuated Force Reference.



Figure 20. Simulation \#3: Actuated Force compared to the reference signal. 


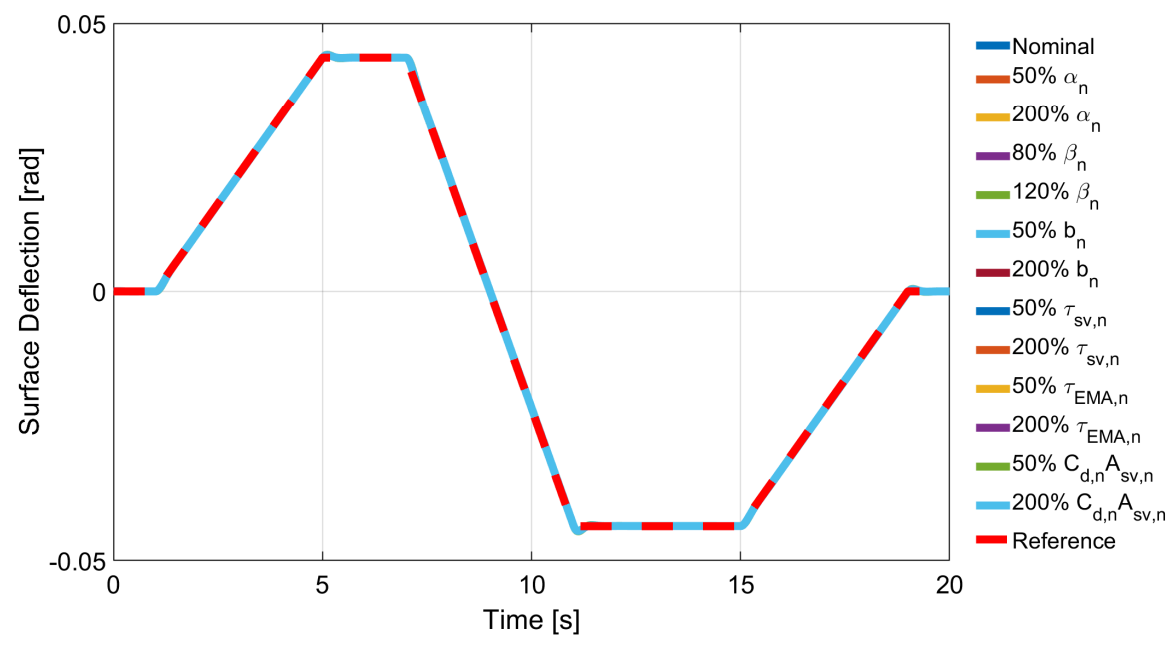

Figure 21. Simulation \#3: Surface Deflection compared to the reference signal.

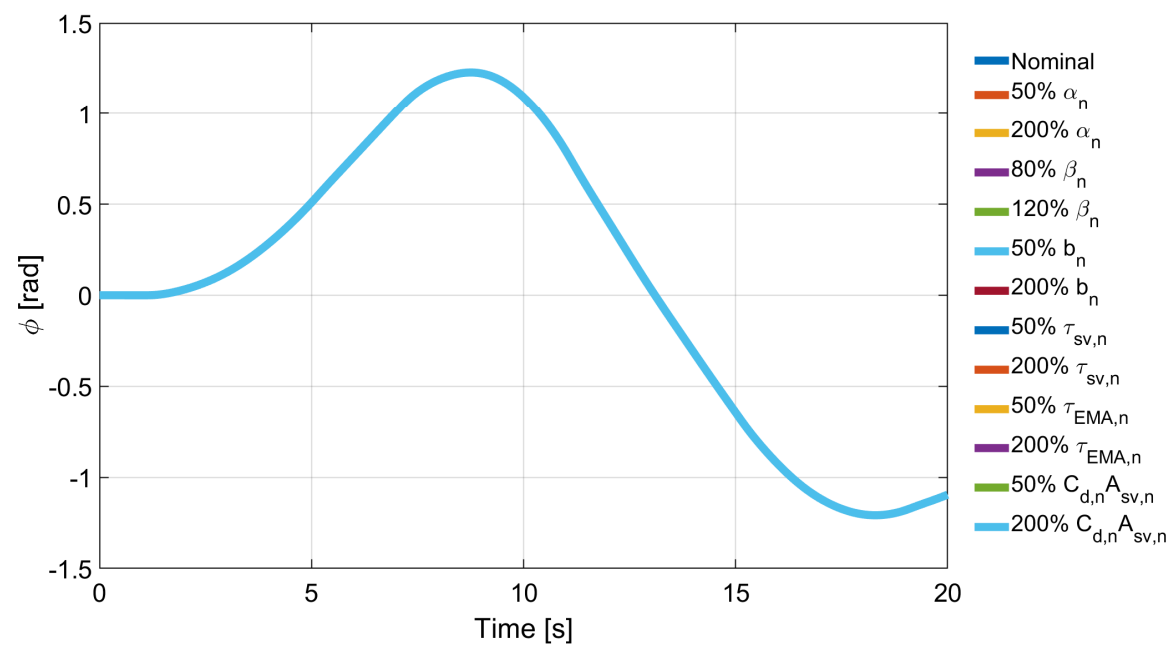

Figure 22. Simulation \#3: Roll Angle from the Aircraft Simulator.

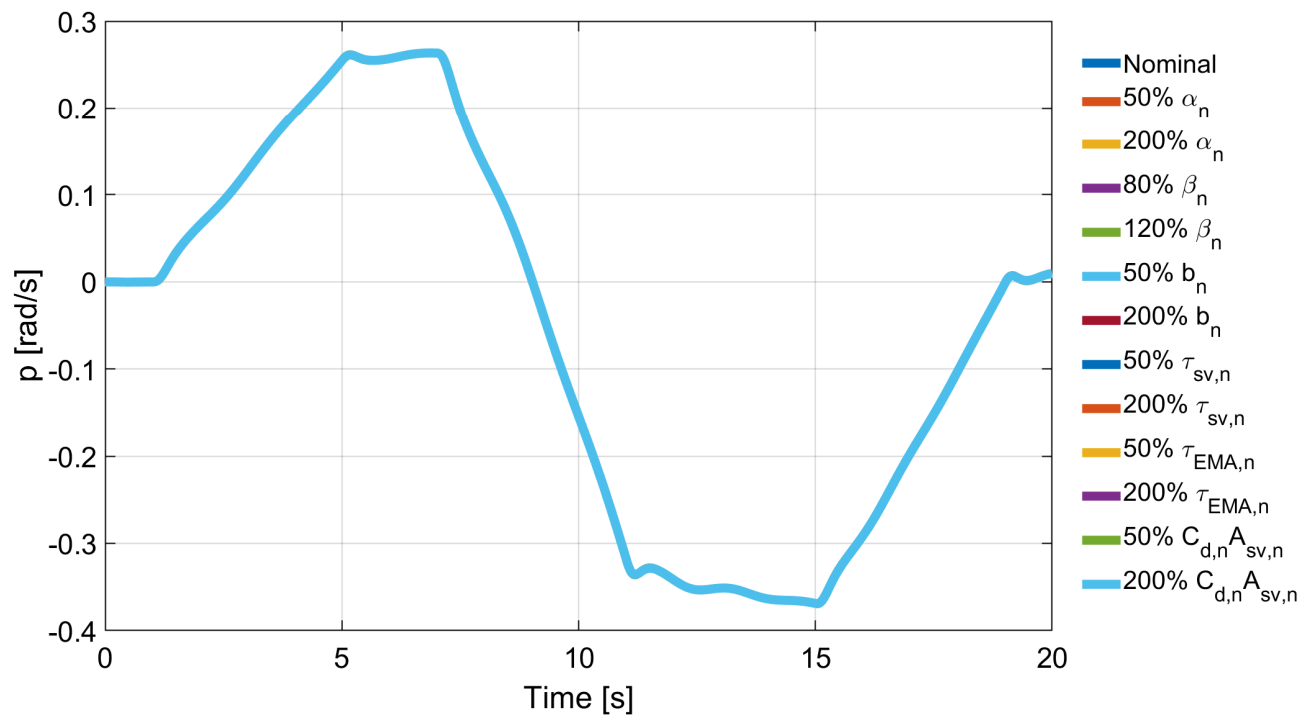

Figure 23. Simulation \#3: Roll Rate from the Aircraft Simulator. 


\section{Conclusions}

This paper describes the control architecture of the Modular Iron Bird which makes use of several test stands to increase flexibility and reduce costs for small commercial aircraft or unmanned aerial vehicles. This iron bird can reproduce preprogrammed loads to test single or multiple actuators, or realistic "in flight" load conditions thanks to the presence of a real time aircraft simulation module.

The design and tuning of the control law needs particular attention because of the concurrent action of both a force controller to guarantee the testing loads and a position controller to control the aerodynamic surface position. This required the use of high quality components, and suggested the use of a dynamic model of the plant during the design phase, to make a robust tuning of the force controller driving the hydraulic actuator.

In the plant design phase, a classical control approach has been adopted. Indeed, the force control algorithm is based on a PID, whose gains have been optimized to ensure robust performance in the presence of parametric uncertainties, and a closed loop response faster ( $\sim 0.01 \mathrm{~s}$ response time) than the EMA position controller ( $\sim 0.1 \mathrm{~s}$ response time). Results proved that the proposed solution works well in the presence of uncertainties and noise and hard nonlinearities neglected in the design of the control law such as hysteresis and dead zones. In particular, both the dynamic and static precision, is quite insensitive to the uncertainties and to the different scenarios considered to include possible tests on different kinds of aircraft.

Author Contributions: Conceptualization, methodology, formal analysis, investigation, writing, E.D., L.E.d.G., I.N., L.B., M.M. Data curation, visualization, software development, E.D., L.E.d.G., I.N. Funding acquisition, supervision M.B., M.M., L.B. All authors have read and agreed to the published version of the manuscript.

Funding: This research was partially funded by REGIONE CAMPANIA, M.I.B. (Modular Iron Bird) project, CUP B43D18000130007, FESR Campania 2014-2020.

Institutional Review Board Statement: Not applicable.

Informed Consent Statement: Not applicable.

Data Availability Statement: Data available on request due to restrictions. The data presented in this study are available on request from the corresponding author. The data are not publicly available due to NDA between Protom Group and university.

Conflicts of Interest: The authors declare no other conflict of interest.

\section{References}

1. Prasad, M.; Gangadharan, K. Aileron endurance test rig design based on high fidelity mathematical modeling. CEAS Aeronaut. J. 2017, 8, 653-671. [CrossRef]

2. Maré, J.C. Aerospace Actuators 2: Signal-By-Wire and Power-By-Wire; John Wiley \& Sons: Hoboken, NJ, USA, 2017.

3. Wheeler, P.; Bozhko, S. The More Electric Aircraft: Technology and challenges. IEEE Electrif. Mag. 2014, 2, 6-12. [CrossRef]

4. Jean-Charles, M.; Jian, F. Review on signal-by-wire and power-by-wire actuation for more electric aircraft. Chin. J. Aeronaut. 2017, 30, 857-870.

5. Wilcox, D.C. Formulation of the kw turbulence model revisited. AIAA J. 2008, 46, 2823-2838. [CrossRef]

6. Rubertus, D.P.; Hunter, L.D. Electromechanical actuation technology for the all-electric aircraft. IEEE Trans. Aerosp. Electr. Syst. 1984, AES-20, 243-249. [CrossRef]

7. Qiao, G.; Liu, G.; Shi, Z.; Wang, Y.; Ma, S.; Lim, T.C. A review of electromechanical actuators for More/All Electric aircraft systems. Proc. Inst. Mech. Eng. Part C J. Mech. Eng. Sci. 2018, 232, 4128-4151. [CrossRef]

8. Brière, D.; Traverse, P. AIRBUS A320/A330/A340 electrical flight controls-A family of fault-tolerant systems. In Proceedings of the FTCS-23 The Twenty-Third International Symposium on Fault-Tolerant Computing, Toulouse, France, 22-24 June 1993; pp. 616-623.

9. Hwang, S.; Choi, S. Ironbird ground test for tilt rotor unmanned aerial vehicle. Int. J. Aeronaut. Space Sci. 2010, 11, $313-318$. [CrossRef]

10. Spangenberg, H.; Vechtel, D. Failure detection, identification and reconfiguration: applications for a modular iron bird. In Proceedings of the AIAA Modeling and Simulation Technologies Conference and Exhibit, Hilton Head, SC, USA, 20-23 August 2007; p. 6466. 
11. De Martin, A.; Jacazio, G.; Sorli, M. Design of a PHM system for electro-mechanical flight controls: a roadmap from preliminary analyses to iron-bird validation. In Proceedings of the MATEC Web of Conferences, EDP Sciences, Sibiu, Romania, 5-7 June 2019; Volume 304, p. 04018.

12. Topczewski, S.; Narkiewicz, J.; Bibik, P. Helicopter Control During Landing on a Moving Confined Platform. IEEE Access 2020, 8, 107315-107325. [CrossRef]

13. Wang, C.; Jiao, Z.; Quan, L. Adaptive velocity synchronization compound control of electro-hydraulic load simulator. Aerosp. Sci. Technol. 2015, 42, 309-321. [CrossRef]

14. Wang, C.; Jiao, Z.; Quan, L. Nonlinear robust dual-loop control for electro-hydraulic load simulator. ISA Trans. 2015, 59, 280-289. [CrossRef]

15. Karpenko, M.; Sepehri, N. Electrohydraulic force control design of a hardware-in-the-loop load emulator using a nonlinear QFT technique. Control Eng. Pract. 2012, 20, 598-609. [CrossRef]

16. Nam, Y. Dynamic Characteristic Analysis and Force Loop Design for the Aerodynamic Load Simulator. KSME Int. J. 2000, 14, 1358-1364. [CrossRef]

17. Yao, B.; Chiu, G.T.; Reedy, J.T. Nonlinear adaptive robust control of one-dof electro-hydraulic servo systems. In ASME International Mechanical Engineering Congress and Exposition (IMECE'97); FPST: Fallon, NV, USA, 1997; Volume 4, pp. 191-197.

18. Yao, B.; Bu, F.; Chiu, G.T. Non-linear adaptive robust control of electro-hydraulic systems driven by double-rod actuators. Int. J. Control 2001, 74, 761-775. [CrossRef]

19. Ullah, N.; Wang, S.; Aslam, J. Adative robust control of electrical load simulator based on fuzzy logic compensation. In Proceedings of the 2011 International Conference on Fluid Power and Mechatronics, Beijing, China, 17-20 August 2011; pp. 861-867.

20. Wang, C.; Jiao, Z.; Wu, S.; Shang, Y. A practical nonlinear robust control approach of electro-hydraulic load simulator. Chin. J. Aeronaut. 2014, 27, 735-744. [CrossRef]

21. Kim, W.; Shin, D.; Won, D.; Chung, C.C. Disturbance-observer-based position tracking controller in the presence of biased sinusoidal disturbance for electrohydraulic actuators. IEEE Trans. Control Syst. Technol. 2013, 21, 2290-2298. [CrossRef]

22. Shang, Y.; Liu, X.; Jiao, Z.; Wu, S. An integrated load sensing valve-controlled actuator based on power-by-wire for aircraft structural test. Aerosp. Sci. Technol. 2018, 77, 117-128. [CrossRef]

23. Wang, L.; Mare, J.C. A force equalization controller for active/active redundant actuation system involving servo-hydraulic and electro-mechanical technologies. Proc. Inst. Mech. Eng. Part G J. Aerosp. Eng. 2014, 228, 1768-1787. [CrossRef]

24. Manring, N.D.; Fales, R.C. Hydraulic Control Systems; John Wiley \& Sons: Hoboken, NJ, USA, 2019.

25. Jelali, M.; Kroll, A. Hydraulic Servo-Systems: Modelling, Identification and Control; Springer Science \& Business Media: Berlin, Germany, 2012.

26. Ali, H.H.; Fales, R.C. A review of flow control methods. Int. J. Dyn. Control 2021, 1-8. [CrossRef]

27. Weerasooriya, S.; El-Sharkawi, M.A. Identification and control of a DC motor using back-propagation neural networks. IEEE Trans. Energy Convers. 1991, 6, 663-669. [CrossRef]

28. Saab, S.S.; Kaed-Bey, R.A. Parameter identification of a DC motor: an experimental approach. In Proceedings of the ICECS 2001 8th IEEE International Conference on Electronics, Circuits and Systems (Cat. No. 01EX483), Malta, Malta, 2-5 September 2001; Volume 2, pp. 981-984. [CrossRef]

29. Rubaai, A.; Kotaru, R. Online identification and control of a DC motor using learning adaptation of neural networks. IEEE Trans. Ind. Appl. 2000, 36, 935-942. [CrossRef]

30. Yassin, I.M.; Taib, M.N.; Rahim, N.A.; Salleh, M.K.M.; Abidin, H.Z. Particle Swarm Optimization for NARX structure selection-Application on DC motor model. In Proceedings of the 2010 IEEE Symposium on Industrial Electronics and Applications (ISIEA), Penang, Malaysia, 3-5 October 2010; pp. 456-462. [CrossRef]

31. Mare, J.C. Dynamic loading systems for ground testing of high speed aerospace actuators. Int. J. Aircr. Eng. Aerosp. Technol. 2006, 78, 275-282. [CrossRef]

32. Jiao, Z.X.; Gao, J.X.; Qing, H.; Wang, S.P. The velocity synchronizing control on the electro-hydraulic load simulator. Chin. J. Aeronaut. 2004, 17, 39-46. [CrossRef]

33. Niksefat, N.; Sepehri, N. Designing robust force control of hydraulic actuators despite system and environmental uncertainties. IEEE Control Syst. Mag. 2001, 21, 66-77.

34. Di Rito, G.; Denti, E.; Galatolo, R. Robust force control in a hydraulic workbench for flight actuators. In Proceedings of the 2006 IEEE Conference on Computer Aided Control System Design, 2006 IEEE International Conference on Control Applications, 2006 IEEE International Symposium on Intelligent Control, Munich, Germany, 4-6 October 2006; pp. 807-813.

35. Conrad, F.; Jensen, C. Design of hydraulic force control systems with state estimate feedback. IFAC Proc. Vol. 1987, 20, 307-312. [CrossRef]

36. Bertucci, A.; Mornacchi, A.; Jacazio, G.; Sorli, M. A force control test rig for the dynamic characterization of helicopter primary flight control systems. Procedia Eng. 2015, 106, 71-82. [CrossRef]

37. Liu, G.; Daley, S. Optimal-tuning PID control for industrial systems. Control Eng. Pract. 2001, 9, 1185-1194. [CrossRef]

38. Jacazio, G.; Balossini, G. Real-time loading actuator control for an advanced aerospace test rig. Proc. Inst. Mech. Eng. Part I J. Syst. Control Eng. 2007, 221, 199-210. [CrossRef]

39. Pan, H.L.; Yan, J. Implement of electro-Hydraulic servo control of aero variable stroke plunger pump. In Advanced Materials Research; Trans Tech Publication: Stafa-Zurich, Switzerland, 2012; Volume 443, pp. 313-318. 
40. Zhu, Z.; Tang, Y.; Shen, G. Experimental investigation of a compound force tracking control strategy for electro-hydraulic hybrid testing system with suppression of vibration disturbances. Proc. Inst. Mech. Eng. Part C J. Mech. Eng. Sci. 2017, 231, 1033-1056. [CrossRef]

41. Bu, F.; Yao, B. Nonlinear adaptive robust control of hydraulic actuators regulated by proportional directional control valves with deadband and nonlinear flow gains. In Proceedings of the 2000 American Control Conference (ACC), Chicago, IL, USA, 28-30 June 2000; Volume 6, pp. 4129-4133.

42. Pratumsuwan, P.; Junchangpood, A. Force and position control in the electro-hydraulic system by using a MIMO fuzzy controller. In Proceedings of the 2013 IEEE 8th Conference on Industrial Electronics and Applications (ICIEA), Melbourne, VIC, Australia, 19-21 June 2013; pp. 1462-1467.

43. Wang, X.; Wang, S.; Wang, X. Electrical load simulator based on velocity-loop compensation and improved fuzzy-PID. In Proceedings of the 2009 IEEE International Symposium on Industrial Electronics, Seoul, Korea, 5-8 July 2009; pp. $238-243$.

44. Li, X.; Zhu, Z.C.; Rui, G.C.; Cheng, D.; Shen, G.; Tang, Y. Force loading tracking control of an electro-hydraulic actuator based on a nonlinear adaptive fuzzy backstepping control scheme. Symmetry 2018, 10, 155. [CrossRef]

45. Gizatullin, A.; Edge, K. Adaptive control for a multi-axis hydraulic test rig. Proc. Inst. Mech. Eng. Part I J. Syst. Control Eng. 2007, 221, 183-198. [CrossRef]

46. Piché, R.; Pohjolainen, S.; Virvalo, T. Design of robust controllers for position servos using H-infinity theory. Proc. Inst. Mech. Eng. Part I J. Syst. Control Eng. 1991, 205, 299-306. [CrossRef]

47. Yao, J.; Jiao, Z.; Shang, Y.; Huang, C. Adaptive nonlinear optimal compensation control for electro-hydraulic load simulator. Chin. J. Aeronaut. 2010, 23, 720-733.

48. Kallu, K.D.; Wang, J.; Abbasi, S.J.; Lee, M.C. Estimated reaction force-based bilateral control between 3dof master and hydraulic slave manipulators for dismantlement. Electronics 2018, 7, 256. [CrossRef]

49. Shi, C.; Wang, X.; Wang, S.; Wang, J.; Tomovic, M.M. Adaptive decoupling synchronous control of dissimilar redundant actuation system for large civil aircraft. Aerosp. Sci. Technol. 2015, 47, 114-124. [CrossRef]

50. Borrelli, M.; D’Amato, E.; di Grazia, L.E.; Mattei, M.; Notaro, I. MPC load control for aircraft actuator testing. In Proceedings of the 2020 7th International Conference on Control, Decision and Information Technologies (CoDIT), Prague, Czech Republic, 29 June-2 July 2020; Volume 1, pp. 587-592. [CrossRef]

51. Drabble, D.; Ponnapalli, P.V.S.; Thomson, M. G.A. Optimisation of PID Controllers-Optimal Fitness Functions. In Developments in Soft Computing; John, R., Birkenhead, R., Eds.; Physica-Verlag HD: Heidelberg, Germany, 2001; pp. $183-190$.

52. Tran, H.K.; Son, H.H.; Duc, P.V.; Trang, T.T.; Nguyen, H.N. Improved Genetic Algorithm Tuning Controller Design for Autonomous Hovercraft. Processes 2020, 8, 66. [CrossRef] 